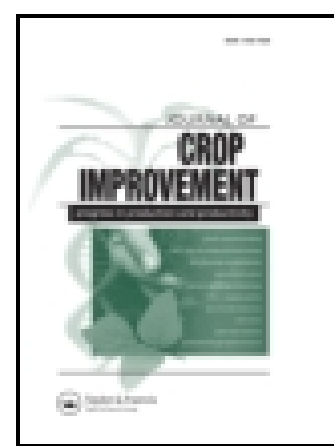

Journal of Crop Improvement

\title{
Modeling the spread of germination of four Mediterranean crops at different temperatures
}

\author{
José A. Andrade, J.F. Cadima \& F.G. Abreu
}

To cite this article: José A. Andrade, J.F. Cadima \& F.G. Abreu (2019): Modeling the spread of germination of four Mediterranean crops at different temperatures, Journal of Crop Improvement, DOI: $10.1080 / 15427528.2019 .1659206$

To link to this article: https://doi.org/10.1080/15427528.2019.1659206

册 Published online: 11 Sep 2019.

Submit your article to this journal $₫$

Q View related articles $₫$

View Crossmark data $\gtrsim$ 


\title{
Modeling the spread of germination of four Mediterranean crops at different temperatures
}

\author{
José A. Andrade $\mathbb{1}^{\mathrm{a}}$, J.F. Cadima ${ }^{\mathrm{b}}$, and F.G. Abreu ${ }^{\mathrm{c}}$ \\ alnstituto de Ciências Agrárias e Ambientais Mediterrâneas (ICAAM) and Departamento de Geociências,

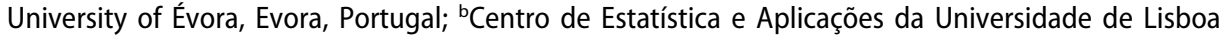 \\ (CEAUL) and Departamento de Ciências e Engenharia de Biossistemas, Instituto Superior de \\ Agronomia, University of Lisbon, Lisbon, Portugal; 'Centro de Estudos Florestais, Instituto Superior de \\ Agronomia, University of Lisbon, Lisbon, Portugal
}

\begin{abstract}
Minimizing the dispersion of germination across time allows greater uniformity during crop development. The aim of this paper was to model the spread of germination, under nonlimiting water conditions and as a function of temperature, of four Mediterranean crops: pea (Pisum sativum L.), broad bean (Vicia faba L.), corn (Zea mays L.) and sorghum (Sorghum vulgare L.). Experiments were performed using a thermogradient plate. Four temperature ranges suitable for the thermal responses of each crop were used. Dispersion was expressed as standard deviation $(\sigma)$ of the frequency distribution of thermal times in the population, modeled by a probit regression and by differences between both accumulated temperatures above the base temperature $\left(\theta_{0.8-} \theta_{0.2}\right)$ or chronological times $\left(\mathrm{t}_{0.8}-\mathrm{t}_{0.2}\right)$ required to reach 0.2 and 0.8 of final germination. Estimates of $\sigma$ were obtained both within thermal ranges defined by applying the plateau-shaped model to the rate vs. temperature relationship and at single temperatures. The differences $\left(\theta_{0.8}-\theta_{0.2}\right)$ and $\left(t_{0.8}\right.$ $-t_{0.2}$ ) were evaluated for each temperature. Reference values were successfully assigned to the germination dispersion of each crop, either to the different thermal ranges used or to single temperatures. Furthermore, a thermal range ensuring minimum values of dispersion was obtained for each crop using a polynomial equation to model the variation of $t_{0.8}-t_{0.2}$ on the set of temperatures used. The dimension of this thermal range was larger for winter than for summer crops. Crop competitiveness depends on the indicators used to assess dispersion. The results allow farmers to choose between different crops and thus optimize germination.
\end{abstract}

\section{ARTICLE HISTORY}

Received 11 July 2019

Accepted 20 August 2019

\section{KEYWORDS}

Dispersion of germination; germination temperature; Mediterranean agriculture; seed germination modeling; thermal time

\section{Introduction}

Individuals of a given seed population do not germinate at the same time nor does germination of such a population progress at a constant rate. Typically, the curve of cumulative germination versus chronological time has a lag period between sowing and the germination of the first seed, which is termed 
as time delay (Hageseth and Cody 1993). This is followed by a period of rapid germination that ends with a marked decrease in the rate of germination (Bahler, Hill, and Byers 1989). Although non-simultaneity of germination across the seed population is a survival strategy (Hsu, Nelson, and Chow 1984), low dispersion across time is required to allow greater uniformity during development and crop duration (Covell et al. 1986). A small dispersion contributes not only to optimization of germination but also to the effectiveness of the various agricultural practices required throughout the crop cycle. Furthermore, short germination times avoid drops in final germination percentages resulting from changes in environmental conditions, which may have an important adaptive value in Mediterranean climates characterized by large daily variations in the near-surface temperature of bare soils and quick changes of soil water content attributable to irregular rainfall and high evaporative demand. As low values of dispersion offer a competitive advantage, knowledge of the characteristic dispersion values of each crop becomes relevant for farmers and may be an important criterion in choosing crops or cultivars.

Despite the similar sigmoidal shape for the germination course of a seed population, differences are visible between different temperatures across the thermal-tolerance range of any crop (Garcia-Huidobro, Monteith, and Squire 1982; Asomaning, Sacande, and Olympio 2011; Pourreza and Bahrani 2012): (a) the lag phase does not always have the same duration; (b) the rate of increase during the rapid growth period is smaller at lower temperatures; and (c) final germination is lower when temperatures are closer to the thermal extremes of the respective tolerance range. To establish the sowing time that optimizes the germination of a given crop, it is useful to know the temperature range that ensures minimum dispersion values or acceptable values from the farmers' point of view, rather than finding only a single temperature that minimizes dispersion. The greater the natural daily and annual variations of soil temperatures, the more relevant this question becomes.

Different methods of assessing the spread of germination have been used (Ranal and Santana 2006). The coefficient of uniformity of germination (Heydecker 1973; Bewley and Black 1994), the time spread of germination (Ducournau et al. 2005; Kader 2005) and the coefficient of variation of the germination time (Carvalho, Santana, and Ranal 2005) are examples of indicators used to measure the variability of germination time within a population of seeds. Despite their simplicity, these indicators have possible drawbacks. All of them assess the dispersion for a single temperature only. The first two methods do not allow comparisons between samples or treatments as the respective germination times are often different. The latter two indicators are sensitive to extreme observations, i.e., those that are closest to the beginning and the end of the time-course of cumulative germination, which are also the phases where errors of observation are largest (Ellis, Simon, and Covell 1987; Ducournau 
et al. 2005). The first indicator (coefficient of uniformity of germination) assumes a normal distribution for the germination frequencies as a function of the chronological time, a condition not verified in most cases.

As the completion of the germination process depends on a chronological time that is "modified" by temperature (thermal time), Covell et al. (1986), Ellis, Simon, and Covell (1987) and Hardegree (2006) evaluated the spread of germination of seed populations of grain legumes and different grasses using the standard deviation of the frequency distribution of thermal times (instead of chronological times, and thus, irrespective of the temperature considered). In this way, the time-courses at all temperatures can be reduced to a single curve by estimating a common base temperature value throughout the whole population (Hardegree 2006). The concept of thermal time is useful to separate the influence of temperature from that of other factors, such as soil moisture, that also act on the dispersion of germination of a crop (Covell et al. 1986; Ellis, Simon, and Covell 1987; Abreu and Clark 1993) and to compare parameters of germination for different crops or genotypes, climates and locations (Garcia-Huidobro, Monteith, and Squire 1982; Mohamed, Clark, and Ong 1988), among other issues. Ellis, Simon, and Covell (1987) assumed the classic triangular-shaped broken-stick model for the germination-temperature relationship to define suboptimal and supraoptimal thermal ranges (Monteith 1977; Garcia-Huidobro, Monteith, and Squire 1982) and applied the probit model to the relationship between cumulative germination and thermal times in each thermal range. Despite undeniable progress, the results obtained with this approach depend on the assumption of a triangular-shaped germination-temperature relation, and on a constant dispersion in each of the thermal ranges. Thus, an evaluation of the dispersion as a function of temperature is still lacking.

In this communication, dispersion of germination under non-limiting water conditions is modeled as a function of the temperature to which the seeds are subjected during the germination process. Different options are presented to evaluate the dispersion either for single temperatures or for thermal intervals defined by a more general piecewise-linear (broken stick) model for the germination rate-temperature relation, the plateau-shaped function of Piper et al. (1996). Dispersion values estimated for single temperatures are also modeled for the entire set of temperatures tested. For this purpose, data on germination behavior in a controlled environment of four Mediterranean crops (pea, broad bean, corn, and sorghum) studied by Andrade, Cadima, and Abreu (2018) were used.

\section{Material and methods}

\section{Seeds}

Seeds of four crops representative of Mediterranean agriculture were used in the germination experiments: pea (Pisum sativum L. var. ballet), broad bean (Vicia 
faba L. var. favel), corn (Zea mays L. var. lorena) and sorghum (Sorghum vulgare L. var. oasis). In Portugal, these varieties of pea and broad bean are usually sown in autumn, whereas those of corn and sorghum are usually sown in spring. All seeds used were provided and certified by relevant ministerial departments of Portugal (Herdade Experimental da Mitra, University of Évora; Estação Nacional de Melhoramento de Plantas, Elvas). Minimum values for the agronomically acceptable (a.a.m.) final germination for each crop are given in Table 1.

\section{Germination experiments}

Germination experiments were performed on a temperature-controlled thermogradient plate built in the Laboratory of Agrometeorology of Lisbon University's Instituto Superior de Agronomia (Ferrão and Abreu 1996), at Lat.: $38^{\circ} 42^{\prime} \mathrm{N}$; Long.: $9^{\circ} 10^{\prime} \mathrm{W}$; Alt.: $54 \mathrm{~m}$. Details regarding these experiments (various materials, design, modus operandi, behavior, accuracy and reproducibility of the thermogradient plate, procedures in handling of seeds and in counts of germination) were described in Andrade, Cadima, and Abreu (2018). Two target ranges of temperatures were imposed according to the known thermal-tolerance range of each crop: $5^{\circ} \mathrm{C}-50^{\circ} \mathrm{C}$ for corn and sorghum and $0^{\circ} \mathrm{C}-45^{\circ} \mathrm{C}$ for pea and broad bean. For all crops, two other temperature ranges $\left(15^{\circ} \mathrm{C}-45^{\circ} \mathrm{C}\right.$ and $\left.15^{\circ} \mathrm{C}-40^{\circ} \mathrm{C}\right)$ were used to obtain additional information on germination at other temperatures near to those where germination rates were found to be high. Table 2 contains the temperatures used to evaluate the germination dispersion of each crop.

Total germination at each temperature was measured and then taken as the corresponding final germination $\left(\mathrm{G}_{\mathrm{f}}\right)$, in percentage of the seeds sown (100 for each crop). Germination was considered high whenever the a.a.m. values were reached (Table 1). Final germination, $\mathrm{G}_{\mathrm{f}}$, is assumed nearly constant across a relatively wide thermal range (Garcia-Huidobro, Monteith, and Squire 1982; Hardegree 2006). Since the time course of cumulative percentage germination approximately follows an S-shaped curve irrespective of temperature, the time $t_{G}$ (in days) required for the germination of a fraction of $G_{f}$ was obtained by linear

Table 1. Agronomically acceptable minimums (a.a.m.) for germination of pea, broad bean, corn and sorghum (Miguel 1983), and agronomic data obtained by (Andrade, Cadima, and Abreu 2018) for those crops: temperatures at which final germinations $\left(G_{f}\right)<$ a.a.m. and mean cardinal temperatures $\left(T_{b}, T_{01}, T_{02}\right.$, and $\left.T_{c}\right)$.

\begin{tabular}{|c|c|c|c|c|c|c|}
\hline \multirow[b]{2}{*}{ Crop } & \multirow{2}{*}{$\begin{array}{c}\text { a.a.m. } \\
(\%)\end{array}$} & \multirow{2}{*}{$\frac{\mathrm{G}_{\mathrm{f}}<\text { a.a.m. }}{\text { Temperatures }\left({ }^{\circ} \mathrm{C}\right)}$} & \multicolumn{4}{|c|}{ Cardinal temperatures (mean values) } \\
\hline & & & $\mathrm{T}_{\mathrm{b}}\left({ }^{\circ} \mathrm{C}\right)$ & $\mathrm{T}_{\mathrm{O} 1}\left({ }^{\circ} \mathrm{C}\right)$ & $\mathrm{T}_{\mathrm{O} 2}\left({ }^{\circ} \mathrm{C}\right)$ & $\mathrm{T}_{\mathrm{C}}\left({ }^{\circ} \mathrm{C}\right)$ \\
\hline Pea & 70 & $6.6,10.3,33.7^{*}$ & 1.7 & 28.2 & 31.7 & 35.8 \\
\hline Broad bean & 80 & $3.8,29.6^{*}, 31.4^{*}$ & 0.2 & 19.6 & 30.8 & 34.8 \\
\hline Corn & 85 & $38.3^{*}, 38.7^{*}, 40.1^{*}$ & 9.3 & 30.4 & 38.9 & 41.8 \\
\hline Sorghum & 70 & $39.1^{*}, 40.5^{*}, 42.1^{*}$ & 10.0 & 32.7 & 38.1 & 46.6 \\
\hline
\end{tabular}

*Temperatures included in the supraoptimal range estimated by Eq.1. 
Table 2. Temperatures (mean \pm standard deviation) used to estimate dispersion of germination for pea, broad bean, corn, and sorghum.

\begin{tabular}{lrrr}
\hline Pea & \multicolumn{1}{c}{ Broad bean } & Corn & Sorghum \\
\hline & \multicolumn{2}{c}{ Temperature $\left({ }^{\circ} \mathrm{C}\right)$} & \\
$6.6 \pm 0.09$ & $3.8 \pm 0.20$ & $11.1 \pm 0.05$ & $10.1 \pm 0.06$ \\
$10.3 \pm 0.05$ & $7.4 \pm 0.06$ & $13.8 \pm 0.05$ & $13.8 \pm 0.09$ \\
$12.5 \pm 0.03$ & $10.5 \pm 0.06$ & $17.3 \pm 007$ & $16.4 \pm 0.09$ \\
$16.0 \pm 0.07$ & $13.9 \pm 0.05$ & $20.2 \pm 0.04$ & $19.7 \pm 0.07$ \\
$19.2 \pm 0.23$ & $17.5 \pm 0.06$ & $23.4 \pm 0.01$ & $22.7 \pm 0.10$ \\
$22.8 \pm 0.12$ & $20.6 \pm 0.09$ & $26.9 \pm 0.04$ & $26.7 \pm 0.07$ \\
$26.2 \pm 0.14$ & $24.0 \pm 0.09$ & $30.7 \pm 0.09$ & $28.5 \pm 0.06$ \\
$28.7 \pm 0.10$ & $25.3 \pm 0.20$ & $31.6 \pm 0.09$ & $31.3 \pm 0.26$ \\
$29.8 \pm 0.21$ & $25.8 \pm 0.24$ & $32.7 \pm 0.04$ & $33.6 \pm 0.11$ \\
$30.5 \pm 0.00$ & $27.2 \pm 0.07$ & $34.4 \pm 0.03$ & $34.3 \pm 0.15$ \\
$33.7 \pm 0.20$ & $29.6 \pm 0.17$ & $36.2 \pm 0.07$ & $36.6 \pm 0.23$ \\
& $31.4 \pm 0.21$ & $38.3 \pm 0.15$ & $39.1 \pm 0.09$ \\
& & $38.7 \pm 0.11$ & $40.5 \pm 0.08$ \\
& & $40.1 \pm 0.08$ & $42.1 \pm 0.11$ \\
\hline
\end{tabular}

interpolation between observed germination percentiles (Covell et al. 1986; Hardegree 2006). The rate of germination $\left(\mathrm{R}_{\mathrm{G}}\right)$ of a fraction of the population was evaluated by the reciprocal of the corresponding time $t_{\mathrm{G}}$.

\section{Analytical procedures}

A piecewise-linear (broken-stick) plateau-shaped function suggested by Piper et al. (1996), relating the germination rate $\left(\mathrm{R}_{\mathrm{G}}\right)$ with temperature $(T)$, was used to obtain the thermal ranges, cardinal temperatures, maximum rates and thermal times required to estimate the spread of germination of each crop. $R_{G}\left(\right.$ in day ${ }^{-1}$ ) for a given fraction of $G_{f}$, is then estimated as follows:

$$
R_{G}(T)=\left\{\begin{array}{c}
R_{\max } \frac{T-T_{b}}{T_{01}-T_{b}}, \text { for } T_{b}<T<T_{01} \\
R_{\max }, \text { for } T_{01} \leq T \leq T_{02} \\
R_{\max } \frac{T_{c}-T}{T_{c}-T_{02}}, \text { for } T_{02}<T<T_{c} \\
0, \text { elsewhere }
\end{array}\right.
$$

where $T_{b}$ is the base temperature, $T_{c}$ the ceiling temperature, and $T_{o 1}$ and $T_{o 2}$ the optimal temperatures that delimit a thermal interval over which the rate is maximal $\left(\mathrm{R}_{\max }\right)$. Rates are zero at temperatures up to and including the base temperature $\left(\mathrm{T}_{\mathrm{b}}\right)$, and at, and above, the ceiling temperature $\left(\mathrm{T}_{\mathrm{c}}\right)$. This model generalizes the earlier triangular-shaped model as parameterized by Ritchie and NeSmith (1991), which is a special case of this model when $T_{o 1}=T_{o 2}$. Values of cardinal temperatures estimated from equation (1) for three fractions of $G_{f}$ $\left(0.2 \mathrm{G}_{\mathrm{f}}, 0.5 \mathrm{G}_{\mathrm{f}}\right.$, and $\left.0.8 \mathrm{G}_{\mathrm{f}}\right)$ of each crop (Andrade, Cadima, and Abreu 2018) were averaged and are shown in Table 1 . These average values are considered the lower and upper limits of the thermal-tolerance range of each crop.

The spread of germination for each crop was estimated for different reference thermal ranges (tolerance interval, suboptimal, supraoptimal, 
optimum intervals as defined below) and for each of the temperatures that were studied.

a) Spread of germination for different thermal ranges.

The spread of germination for the four crops under study was evaluated in the tolerance range $] \mathrm{T}_{\mathrm{b}}, \mathrm{T}_{\mathrm{c}}[$, which can be partitioned into the suboptimal $] \mathrm{T}_{\mathrm{b}}$, $\mathrm{T}_{\mathrm{o} 1}$ [, the optimal [ $\mathrm{T}_{\mathrm{o} 1}, \mathrm{~T}_{\mathrm{o} 2}$ ] and the supraoptimal] $\mathrm{T}_{\mathrm{o} 2}, \mathrm{~T}_{\mathrm{c}}$ [ranges. Considering the poorer quality of the fitted relation between rate and temperature for values close to $\mathrm{T}_{\mathrm{b}}$ (Hsu, Nelson, and Chow 1984; Garcia-Huidobro, Monteith, and Squire 1982; Covell et al. 1986; Marshall and Squire 1996), the dataset in the suboptimal range was defined in two different ways, depending on whether or not the lowest temperature tested was considered. Whenever it is necessary to distinguish them, this latter definition will be referred to as the "narrow suboptimal range" (] $\mathrm{T}_{\mathrm{b}}, \mathrm{T}_{\mathrm{ol}}$ [') and the former as "broad suboptimal range" (] $\mathrm{T}_{\mathrm{b}}, \mathrm{T}_{\mathrm{o} 1}[)$.

Probit analysis is a specific instance of a Generalized Linear Model (McCullaugh and Nelder 1989). It was used here to model the relationship between percentiles of cumulative germination and thermal times for each thermal range described above. It assumes that the cumulative germination $(G)$ is a cumulative distribution function $\Phi$ of a standardized normal distribution, applied to a linear transformation of thermal time (Covell et al. 1986). The underlying assumption is that thermal time until germination has, in the seed population, a normal distribution, $\mathrm{N}(\mu, \sigma)$, with mean thermal time to germination $\mu$ and standard deviation $\sigma$ (in ${ }^{\circ} \mathrm{Cd}$ ). Thus, cumulative germination is modeled as:

$$
G=\Phi\left(b_{0}+b_{1} \theta\right)
$$

where $b_{0}$ and $b_{1}$ are the parameters that define the appropriate linear transformation of thermal time. The linear transformation in equation (2) corresponds to standardizing thermal times. In other words, we assume that the probit transformation of cumulative germination, $\Phi^{-1}(\mathrm{G})$, is given by:

$$
\Phi^{-1}(\mathrm{G})=\mathrm{b}_{0}+\mathrm{b}_{1} \theta=\frac{\theta-\mu}{\sigma}
$$

so that $b_{1}=\frac{1}{\sigma}$ and $b_{0}=\frac{-\mu}{\sigma}$. Thus, $\sigma=\frac{1}{b_{1}}$ is the standard deviation of the frequency distribution of thermal times in the population and is an indicator of dispersion, that is called the dispersion value, which represents the sensitivity of the population to thermal time, $\theta$. Likewise, $\frac{-1}{b_{0}}=\frac{\sigma}{\mu}$ is the corresponding coefficient of variation $\left(\mathrm{CV}_{\theta}\right)$. Standard GLM asymptotic theory for maximum likelihood estimators can be used to obtain approximate confidence intervals for $b_{1}$ and $b_{0}$, and by taking reciprocals of the endpoints (and multiplying by -1 in the case of $b_{0}$ ), for the dispersion value, $\sigma$, and $\mathrm{CV}_{\theta}$.

Although the use of $\ln \theta$ instead of $\theta$ may improve goodness-of-fit (Pritchard and Manger 1990; Hardegree 2006), the differences in our case 
were not substantial (results not shown). This did not justify transforming the scale of thermal time.

Thermal time $(\theta)$ for germination in the suboptimal range, i.e., the accumulated temperature (in ${ }^{\circ} \mathrm{Cd}$ ) above base temperature $\left(\mathrm{T}_{\mathrm{b}}\right)$ required by a given fraction of $\mathrm{G}_{\mathrm{f}}$ to germinate (Monteith 1977), is assumed to be constant between $\mathrm{T}_{\mathrm{b}}$ and $\mathrm{T}_{\mathrm{o} 1}$. Across this range, it was estimated as the reciprocal of the slope in the ascending portion of model (1), that is, as $\theta_{1}=$ $\left(\mathrm{T}_{\mathrm{o} 1}-\mathrm{T}_{\mathrm{b}}\right) / \mathrm{R}_{\max }$. Since the chronological time required to germinate a given fraction of $G_{f}\left(t_{G}\right)$ is the reciprocal of the rate of germination $R_{G}$, the ascending portion of model (1) can be written as the following equation:

$$
\theta_{1}=\mathrm{t}_{\mathrm{G}}\left(\mathrm{T}-\mathrm{T}_{\mathrm{b}}\right)\left({ }^{\circ} \mathrm{Cd}\right)
$$

Equation 4 is used to calculate the thermal time as a function of $t_{G}$ for temperatures between $\mathrm{T}_{\mathrm{o} 1}$ and $\mathrm{T}_{\mathrm{o} 2}$ (optimal range), where $\theta$ is no longer constant. In this range, for each fraction of $\mathrm{G}_{\mathrm{f}}$, thermal time increases with temperature. For temperatures in the supraoptimal range (above $\mathrm{T}_{\mathrm{o} 2}$ ), thermal time is again assumed to be constant $\left(\theta_{2}\right)$ as the reciprocal of negative slope in the descending portion of model (1), that is, $\theta_{2}=\left(\mathrm{T}_{\mathrm{c}}-\mathrm{T}_{\mathrm{o} 2}\right) / \mathrm{R}_{\max }$. This is consistent with the equation in Garcia-Huidobro, Monteith, and Squire (1982):

$$
\theta_{2}=\mathrm{t}_{\mathrm{G}}\left(\mathrm{T}_{\mathrm{c}}-\mathrm{T}\right)\left({ }^{\circ} \mathrm{Cd}\right)
$$

For a given percentile germinated, values of $\theta_{2}$ for the supraoptimal range can be expressed as a function of $\theta_{1}$ for the suboptimal range, using a useful transformation suggested by Garcia-Huidobro, Monteith, and Squire (1982) for the triangular-shaped model. This transformation was extended in the present work to the plateau-shaped model as:

$$
\theta_{2}=\frac{T_{c}-T_{02}}{T_{01}-T_{b}} \theta_{1}\left({ }^{\circ} \mathrm{Cd}\right)
$$

Thermal times were estimated from mean values of $\mathrm{T}_{\mathrm{b}}$ or $\mathrm{T}_{\mathrm{c}}$ showed in Table 1 . The standard method of assessing the goodness-of-fit of a Probit analysis involves its residual deviance. This can be compared with the residual deviance of a null model (the model without explanatory variables), using the Likelihood Ratio Test (McCulloch, Searle, and Neuhaus 2008). Alternatively, Akaike's Information Criteria (AIC) can also be used as an indicator of goodness-of-fit (Akaike 1998).

Because the germination speed differs considerably between different crops (Andrade, Cadima, and Abreu 2018), the variability in dispersion of germination must also be characterized by a dimensionless parameter that expresses its relative dispersion $\left(\mathrm{CV}_{\theta}\right)$, and not only by its absolute dispersion $(\sigma) . \mathrm{CV}_{\theta}$, the ratio between the absolute dispersion $(\sigma)$ and the mean thermal time $(\mu)$, was thus also evaluated. 
b) Spread of germination at single temperatures

Spread of germination for each temperature used was also estimated by using probit analysis to model the relationship between percentiles of cumulative germination and thermal times. Also in this context, both $\sigma$ and $\mathrm{CV}_{\theta}$ were evaluated.

Differences between thermal times required to reach $0.2 \mathrm{G}_{\mathrm{f}}$ and $0.8 \mathrm{G}_{\mathrm{f}}$ $\left(\theta_{0.8}-\theta_{0.2}\right)$ were also used to assess the spread of germination at single temperatures. Because chronological time is a central factor in the variation of different environmental parameters that strongly affect the germination process under field conditions (e.g., the water content in the soil) and may have more practical meaning for farmers, dispersion was also estimated for each crop by the differences between chronological times corresponding to the germination of $20 \%\left(0.2 \mathrm{G}_{\mathrm{f}}\right)$ and $80 \%\left(0.8 \mathrm{G}_{\mathrm{f}}\right)$ of seed sown, that is, by $\mathrm{t}_{0.8}-\mathrm{t}_{0.2}$. It is assumed that $\theta_{0.8}-\theta_{0.2}$, or the corresponding time elapsed $t_{0.8}-t_{0.2}$, are measures of the phase along which more seeds germinate per unit of time. The fraction $0.8 \mathrm{G}_{\mathrm{f}}$ represents an approximate value above which the number of germinated seeds per unit of time decreases considerably (Hsu, Nelson, and Chow 1984). Furthermore, it represents an agronomically satisfactory final proportion for most crop, whenever $G_{f}$ is close to the maximum. The fraction $0.2 G_{f}$ was also considered, as it is a fraction that overcomes the usual difficulties in fitting the early part of the cumulative germination curve. Furthermore, frequent errors of observation associated with the measurements of the germination of the initial and final seeds can be avoided by focusing on these fractions. A rough assessment of the statistical significance of differences between the estimates of the parameters in different contexts was made considering the overlaps of their respective $95 \%$ confidence intervals.

\section{Results}

\section{Spread of germination for different thermal ranges}

Both the mean values of thermal time for germination and the dispersion around it vary with the type of crop (Figure 1). The course of germination, as a function of the thermal time $(\theta)$ for the thermal-tolerance range considered for each crop, was successfully fitted by a probit regression $\left({ }^{*} \mathrm{P}<0.0001\right)$. Thus, it is possible to quantify the dispersion in the thermal-tolerance range of each crop ( $\sigma$, in Eq.2) by a single value. Despite the high statistical significance found in all the contexts, the goodness-of-fit was better for pea than for the other crops (Table 3 ). In fact, the use of $\theta$ as a predictive variable decreased the value of the residual deviation of the null model by $84 \%$ in the case of the pea and by approximately $73 \%, 75 \%$, and $67 \%$ in the cases of broad bean, corn, and sorghum, respectively. As shown in Table 4, the 


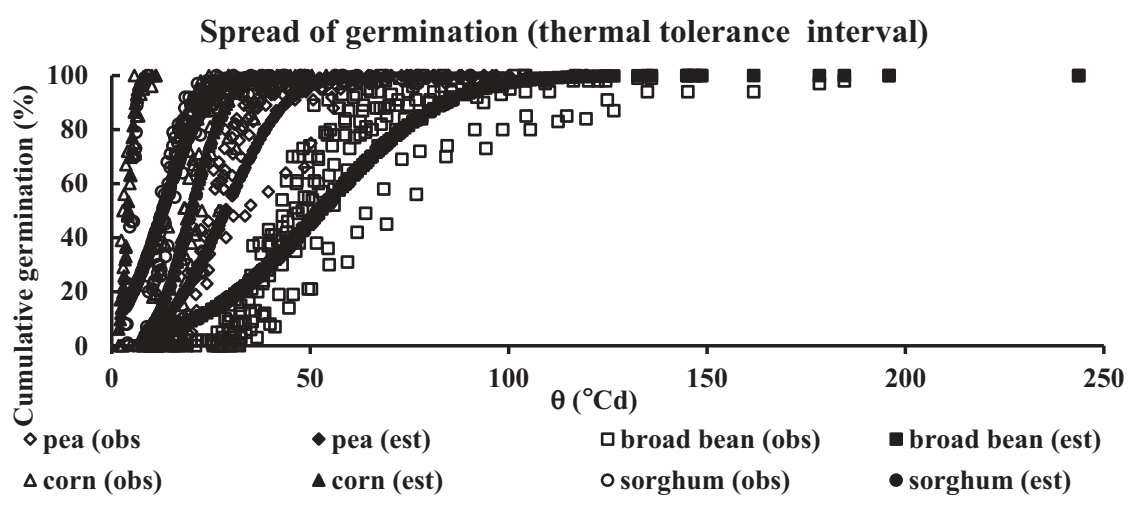

Figure 1. Observed (open symbols) and estimated (solid symbols) responses of cumulative germination $(G, \%)$ to the thermal times $(\theta)$, referred to the thermal tolerance intervals considered for pea, broad bean, corn, and sorghum.

Table 3. Evaluation of spread of germination for thermal ranges (tolerance, board suboptimal, narrow suboptimal, optimal, supraoptimal)* defined for pea, broad bean, corn and sorghum by using a probit regression: estimates (est.) of coefficients ( $b_{0}$-Intercept and $\left.1 / \sigma-s l o p e\right)$ and respective standard errors (SE), measures of goodness-of-fit (null and residual deviance and respective degrees of freedom (d.f.) and AIC (Akaike Information Criterion)).*See meaning in the text.

\begin{tabular}{|c|c|c|c|c|c|c|c|c|c|c|}
\hline \multirow[b]{2}{*}{ Crop } & \multirow[b]{2}{*}{ Thermal ranges } & \multicolumn{2}{|c|}{$b_{0}$} & \multicolumn{2}{|c|}{$1 / \sigma$} & \multicolumn{2}{|c|}{ Null deviance } & \multicolumn{2}{|c|}{ Residual deviance } & \multirow[b]{2}{*}{ AIC } \\
\hline & & est. & SE & est. & SE & value & d.f. & value & d.f. & \\
\hline \multirow[t]{5}{*}{ Pea } & Tolerance & -2.38 & 0.035 & 0.08 & 0.001 & $14,380.0$ & 198 & 2266.0 & 197 & 2926.0 \\
\hline & Board suboptimal & -2.34 & 0.039 & 0.08 & 0.001 & $11,530.0$ & 155 & 1790.0 & 154 & 2307.0 \\
\hline & Narrow suboptimal & -2.43 & 0.048 & 0.09 & 0.002 & 9032.5 & 127 & 1394.3 & 126 & 1805.5 \\
\hline & Optimal & -2.53 & 0.102 & 0.09 & 0.003 & 1806.0 & 27 & 314.4 & 26 & 408.1 \\
\hline & Supraoptimal & -3.44 & 0.170 & 0.86 & 0.039 & 989.1 & 14 & 10.6 & 13 & 67.9 \\
\hline \multirow{5}{*}{$\begin{array}{l}\text { Broad } \\
\text { bean }\end{array}$} & Tolerance & -2.14 & 0.029 & 0.04 & 0.001 & $15,215.7$ & 232 & 4067.7 & 231 & 4918.0 \\
\hline & Board suboptimal & -3.47 & 0.059 & 0.07 & 0.001 & 7596.0 & 109 & 634.1 & 108 & 1031.0 \\
\hline & Narrow suboptimal & -3.51 & 0.073 & 0.08 & 0.002 & 5641.0 & 84 & 492.0 & 83 & 798.1 \\
\hline & Optimal & -2.00 & 0.043 & 0.03 & 0.001 & 6183.0 & 104 & 1408.0 & 103 & 1800.0 \\
\hline & supraoptimal & -3.15 & 0.125 & 0.34 & 0.013 & 1186.0 & 17 & 34.6 & 16 & 104.2 \\
\hline \multirow[t]{5}{*}{ Maize } & tolerance & -2.75 & 0.044 & 0.14 & 0.002 & $10,240.0$ & 145 & 2528.0 & 144 & 3011.0 \\
\hline & board suboptimal & -3.66 & 0.073 & 0.19 & 0.004 & 5606.4 & 77 & 1077.6 & 76 & 1344.3 \\
\hline & narrow suboptimal & -4.71 & 0.104 & 0.24 & 0.005 & 4588.6 & 61 & 386.2 & 60 & 594.2 \\
\hline & optimal & -3.07 & 0.105 & 0.14 & 0.004 & 2729.0 & 38 & 572.2 & 37 & 686.2 \\
\hline & supraoptimal & -1.87 & 0.079 & 0.47 & 0.018 & 1431.0 & 28 & 357.1 & 27 & 447.6 \\
\hline \multirow[t]{5}{*}{ Sorghum } & tolerance & -1.46 & 0.030 & 0.11 & 0.002 & $10,427.5$ & 165 & 3456.0 & 164 & 4008.0 \\
\hline & board suboptimal & -1.41 & 0.036 & 0.12 & 0.002 & 7043.0 & 108 & 2499.0 & 107 & 2862.0 \\
\hline & narrow suboptimal & -2.76 & 0.064 & 0.19 & 0.004 & 5696.1 & 92 & 675.4 & 91 & 980.0 \\
\hline & optimal & -1.50 & 0.087 & 0.10 & 0.005 & 1492.3 & 25 & 424.1 & 24 & 510.5 \\
\hline & supraoptimal & -2.02 & 0.081 & 0.37 & 0.013 & 1858.2 & 30 & 296.2 & 29 & 406.9 \\
\hline
\end{tabular}

absolute $(\sigma)$ and relative dispersion $\left(\mathrm{CV}_{\theta}\right)$ values were also different for the four crops (their confidence intervals never overlapped). According to the admissible values given by $95 \%$ confidence intervals, the value of $\sigma$ for broad bean (between 24.01 and $25.17^{\circ} \mathrm{Cd}$ ) was the largest found among the four crops. For pea, the value of $\sigma$ (between 11.75 and $12.36^{\circ} \mathrm{Cd}$ ) was larger than those found for sorghum $\left(8.52\right.$ to $\left.9.05^{\circ} \mathrm{Cd}\right)$ and corn $\left(7.02\right.$ to $\left.7.45^{\circ} \mathrm{Cd}\right)$. 
Table 4. Parameters from the probit regression used to evaluate the spread of germination for thermal ranges (tolerance, board suboptimal, narrow suboptimal, optimal, and supraoptimal)* defined for pea, board bean, corn and sorghum: the most likely values of $\theta(\mu)$, estimates (est.) of absolute $(\sigma)$ and relative dispersion $\left(\mathrm{CV}_{\theta}\right)$ and corresponding $95 \%$ confidence intervals (c.i.). ${ }^{*}$ See meaning in the text.

\begin{tabular}{|c|c|c|c|c|c|c|}
\hline \multirow[b]{2}{*}{ Crop } & \multirow[b]{2}{*}{ Thermal ranges } & \multirow{2}{*}{$\frac{\mu}{\left({ }^{\circ} \mathrm{Cd}\right)}$} & \multicolumn{2}{|c|}{ Absolute dispersion $(\sigma)$} & \multicolumn{2}{|c|}{ Relative dispersion $\left(\mathrm{CV}_{\theta}\right)$} \\
\hline & & & est. $\left({ }^{\circ} \mathrm{Cd}\right)$ & $95 \%$ c.i. $\left({ }^{\circ} \mathrm{Cd}\right)$ & est. & 95\% c.i. \\
\hline \multirow[t]{5}{*}{ Pea } & Tolerance & 28.7 & 12.0 & {$[11.75 .12 .36]$} & 0.42 & [0.41. 0.43] \\
\hline & Board suboptimal & 29.0 & 12.4 & [12.05. 12.76] & 0.43 & {$[0.41 .0 .44]$} \\
\hline & Narrow suboptimal & 28.0 & 11.5 & [11.16. 11.90] & 0.41 & {$[0.40 .0 .43]$} \\
\hline & Optimal & 29.4 & 11.6 & [10.83. 12.44] & 0.39 & {$[0.37 .0 .43]$} \\
\hline & Supraoptimal & 4.0 & 1.2 & [1.06. 1.27] & 0.29 & {$[0.26 .0 .32]$} \\
\hline Broad & Tolerance & 52.6 & 24.6 & [24.01.25.17] & 0.47 & {$[0.46 .0 .48]$} \\
\hline \multirow[t]{4}{*}{ bean } & Board suboptimal & 46.9 & 13.5 & [13.07. 13.95] & 0.29 & {$[0.28 .0 .30]$} \\
\hline & Narrow suboptimal & 45.7 & 13.0 & [12.53. 13.54] & 0.28 & {$[0.27,0.30]$} \\
\hline & Optimal & 60.1 & 30.1 & [29.06. 31.24] & 0.50 & {$[0.48 .0 .52]$} \\
\hline & Supraoptimal & 9.4 & 3.0 & [2.77. 3.23] & 0.32 & {$[0.29 .0 .34]$} \\
\hline \multirow[t]{5}{*}{ Maize } & Tolerance & 19.9 & 7.2 & [7.02. 7.45] & 0.36 & {$[0.35,0.38]$} \\
\hline & Board suboptimal & 18.9 & 5.2 & {$[4.97 .5 .37]$} & 0.27 & {$[0.26 .0 .28]$} \\
\hline & Narrow suboptimal & 20.0 & 4.2 & {$[4.07 .4 .43]$} & 0.21 & {$[0.20 .0 .22]$} \\
\hline & Optimal & 22.2 & 7.2 & {$[6.82 .7 .67]$} & 0.33 & {$[0.30 .0 .35]$} \\
\hline & Supraoptimal & 4.0 & 2.1 & {$[2.00 .2 .31]$} & 0.53 & {$[0.49 .0 .58]$} \\
\hline \multirow[t]{5}{*}{ Sorghum } & Tolerance & 12.8 & 8.8 & {$[8.52 .9 .05]$} & 0.68 & {$[0.66 .0 .71]$} \\
\hline & Board suboptimal & 11.9 & 8.5 & {$[8.15 .8 .77]$} & 0.71 & {$[0.68,0.74]$} \\
\hline & Narrow suboptimal & 14.6 & 5.3 & [5.06. 5.47] & 0.36 & {$[0.35 .0 .38]$} \\
\hline & Optimal & 15.3 & 10.2 & [9.41. 11.09] & 0.67 & {$[0.60 .0 .75]$} \\
\hline & Supraoptimal & 5.4 & 2.7 & {$[2.53 .2 .89]$} & 0.50 & {$[0.46 .0 .54]$} \\
\hline
\end{tabular}

Regarding the values of the relative dispersion $\left(\mathrm{CV}_{\theta}\right)$ in the same thermal range, sorghum showed the highest estimated value (0.68), whereas the other crops had values ranging from 0.36 (corn) to 0.47 (broad bean).

Also, for each sub-range considered (suboptimal, optimal, and supraoptimal thermal ranges), the probit regression successfully described $\left({ }^{*} \mathrm{P}<0.0001\right)$ the course of germination as a function of $\theta$ (Figure 2). Thus, it was also possible to quantify the dispersion of each crop (by $\sigma$, in Eq.2), regardless of the predefined thermal range considered. The model considerably reduced the value of the null model's residual deviance in all cases (Table 3), with the smallest gains being for sorghum ( $75 \%$ and $72 \%$, when both suboptimal and optimal ranges were considered, respectively) and for corn (75\%, when the model was used for the supraoptimal range). Whenever the lowest experimental temperature was not considered in each suboptimal interval (narrow suboptimal range), the goodness-of-fit did not change significantly in the case of winter crops, but it improved substantially for the summer crops. For each crop, the quality of prediction for the sub-ranges was generally greater than that observed for the full thermal-tolerance range of each crop.

Dispersion values for any crop vary with the sub-thermal ranges considered (Figure 2). Differences were statistically relevant in most cases (the 95\% confidence intervals overlapped only in the optimal and suboptimal ranges 

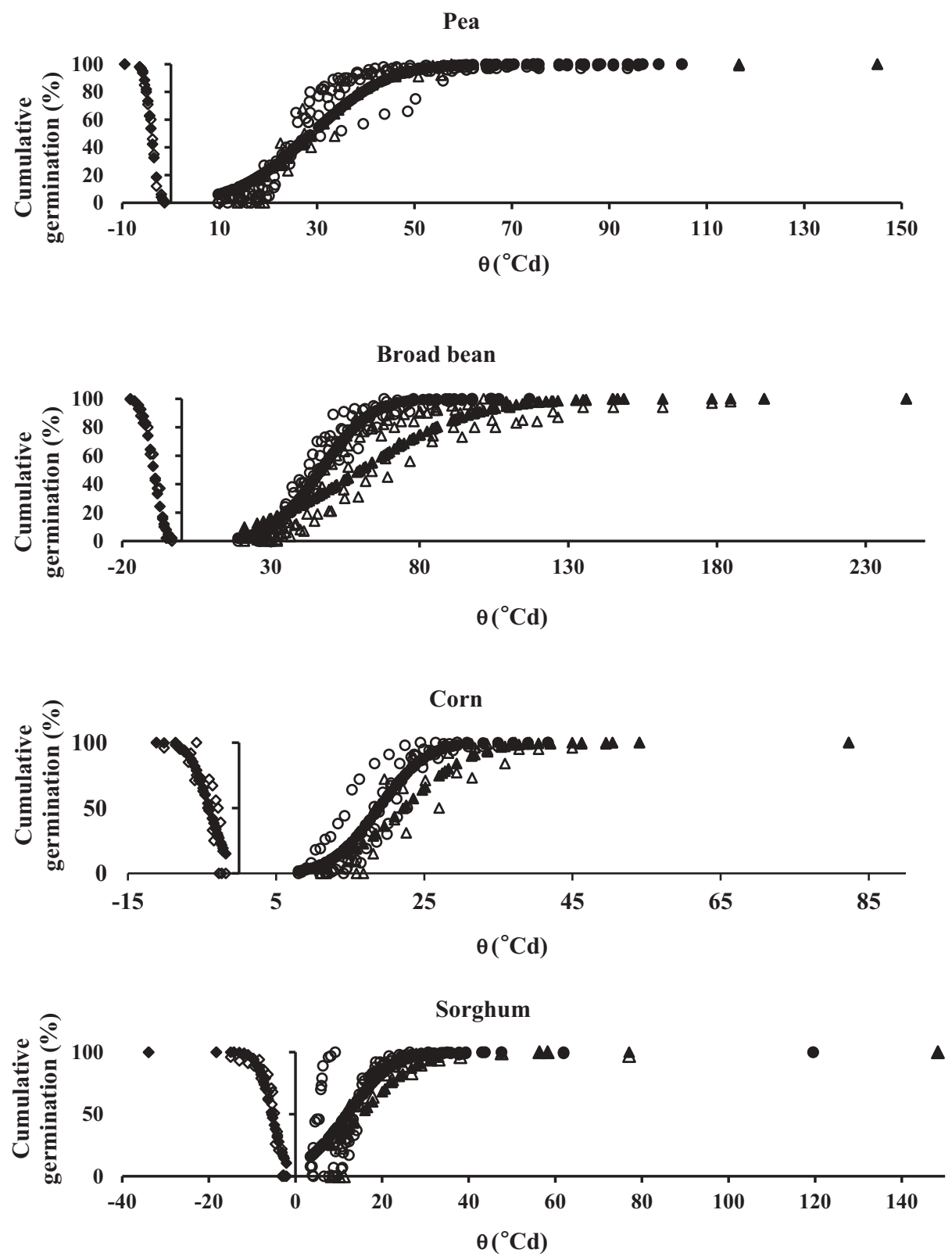

Figure 2. Observed (open symbols) and estimated (solid symbols) responses of cumulative germination $\left(\% \mathrm{G}_{\mathrm{f}}\right)$ to thermal time $\left(\theta^{\circ} \mathrm{Cd}\right)$ for different thermal subranges of pea, board bean, corn, and sorghum. Estimated values are derived from probit analysis used (Eq.3). $\bigcirc$ (board suboptimal range observed), $\bullet$ (board suboptimal range estimated), $\Delta$ (optimal range observed), $\Delta$ (optimal range estimated), $\diamond$ (supraoptimal observed), (supraoptimal range estimated). Note: $\theta$ referred to supraoptimal ranges are presented here with negative values.

for pea) (Table 4). Dispersion for supraoptimal ranges always presented the smallest values ( $\leq 3^{\circ} \mathrm{Cd}$ in any case), whereas that for optimal ranges generally presented the largest values (always $>7^{\circ} \mathrm{Cd}$ for any crop). Decreases in $\sigma$ were 
always observed whenever the lowest temperature of the suboptimal range was excluded (narrow suboptimal range), although the decreases were relevant only for pea, corn, and sorghum. Values of $\sigma$ found for the different sub-ranges were generally lower than those found for the full thermaltolerance ranges (only those obtained for the suboptimal range of pea and for the optimal ranges of broad bean and sorghum were greater) of the same crop.

For both suboptimal and optimal ranges, winter crops presented the largest estimated values of $\sigma\left(\geq 11.5^{\circ} \mathrm{Cd}\right.$ in all cases $)$ and summer crops the lowest (generally $<10^{\circ} \mathrm{Cd}$ ). Broad bean presented the greatest values of absolute dispersion, ranging from $\left.13.0^{\circ} \mathrm{Cd}(] \mathrm{T}_{\mathrm{b}}, \mathrm{T}_{\mathrm{o} 1}{ }^{\prime}\right)$ to $30.1^{\circ} \mathrm{Cd}\left(\left[\mathrm{T}_{\mathrm{o} 1}\right.\right.$, $\left.\mathrm{T}_{\mathrm{o} 2}\right]$ ) whereas corn always had the smallest values, ranging from $4.2^{\circ} \mathrm{Cd}$ (] $\mathrm{T}_{\mathrm{b}}, \mathrm{T}_{\mathrm{o} 1}$ ') to $7.2^{\circ} \mathrm{Cd}\left(\left[\mathrm{T}_{\mathrm{o} 1}, \mathrm{~T}_{\mathrm{o} 2}\right]\right)$ (Table 4). Dispersion values $(\sigma)$ for supraoptimal ranges varied between $1.2^{\circ} \mathrm{Cd}$ (pea) and $3.0^{\circ} \mathrm{Cd}$ (broad bean). The $95 \%$ confidence intervals for $\sigma$ values did not overlap in most cases (only the optimal ranges of pea and sorghum and the supraoptimal ranges of sorghum and broad bean overlapped).

Values of $\mathrm{CV}_{\theta}$ also varied with the type of crop and, for each crop, with the thermal range considered (Table 4). However, no general trend was found when any of these factors were taken into account: they ranged from 0.29 (] $\mathrm{T}_{\mathrm{o} 2}, \mathrm{~T}_{\mathrm{c}}[)$ to 0.43(] $\mathrm{T}_{\mathrm{b}}, \mathrm{T}_{\mathrm{o} 1}$ l) for pea, from 0.28(] $\mathrm{T}_{\mathrm{b}}, \mathrm{T}_{\mathrm{o} 1}$ l') $^{\prime}$ to $0.50\left(\left[\mathrm{~T}_{\mathrm{o} 1}, \mathrm{~T}_{\mathrm{o} 2}\right]\right)$ for broad bean, from 0.21(] $\mathrm{T}_{b}, \mathrm{~T}_{\mathrm{o} 1}\left[\right.$ ') to 0.53(] $\left.\mathrm{T}_{\mathrm{o} 2}, \mathrm{~T}_{\mathrm{c}} \mathrm{l}\right)$ for corn and from 0.36 (] $\left.\mathrm{T}_{\mathrm{b}}, \mathrm{T}_{\mathrm{o} 1}{ }^{\prime}\right)$ to 0.71(] $\mathrm{T}_{\mathrm{b}}, \mathrm{T}_{\mathrm{o} 1}$ l) for sorghum. In any case, the relative dispersion always decreased (significantly in the cases of summer crops) when narrow suboptimal range was considered instead of broad suboptimal range).

\section{Spread of germination at single temperatures}

a) Absolute $(\sigma)$ and relative $\left(\mathrm{CV}_{\theta}\right)$ dispersions

The course of germination of any crop, as a function of the thermal time $(\theta)$, was well-fitted by a probit regression $\left({ }^{*} \mathrm{P}<0.0001\right)$, irrespective of the temperature considered. The goodness-of-fit was quite high in all cases tested: in 36 of the 51 simulations, the introduction of $\theta$ as the predictor variable decreased the residual deviation of the null model by at least $90 \%$ and in only one case (sorghum at $36.6^{\circ} \mathrm{C}$ ) was the decrease smaller than $80 \%$ (Table 5). Thus, it is also possible to quantify the germination dispersion of the four crops at individual temperatures as the standard deviation of the frequency distribution of $\theta$ required for the germination of a seed population.

The dispersion values $(\sigma)$ of any crop were close to their minimum values across a relatively wide thermal range (Figure 3 and Table 6). Furthermore, they showed a more or less visible tendency to increase slightly for temperatures above $25^{\circ} \mathrm{C}$ in the case of winter crops (mainly broad bean) and above $34^{\circ} \mathrm{C}$ for summer crops (both these temperatures belong to the respective 
Table 5. Evaluation of spread of germination as a function of temperature (T) by using probit analysis, for pea, broad bean, corn and sorghum: estimates (est.) of coefficients ( $\mathrm{b}_{0}$-Intercept and $1 / \sigma$-slope) and respective standard errors (SE), measures of goodness-of-fit (null and residual deviance and respective degrees of freedom (d.f.) and AIC (Akaike Information Criterion)).

\begin{tabular}{|c|c|c|c|c|c|c|c|c|c|c|}
\hline \multirow[b]{2}{*}{ Crops } & \multirow{2}{*}{$\frac{\text { Temperatures }}{\left({ }^{\circ} \mathrm{C}\right)}$} & \multicolumn{2}{|c|}{$\mathrm{b}_{0}$} & \multicolumn{2}{|c|}{$1 / \sigma$} & \multicolumn{2}{|c|}{ Null deviance } & \multicolumn{2}{|c|}{ Residual deviance } & \multirow[b]{2}{*}{ AIC } \\
\hline & & est. & SE & est. & SE & value & d.f. & value & d.f. & \\
\hline \multirow[t]{11}{*}{ Pea } & 6.6 & -2.15 & 0.065 & 0.06 & 0.002 & 1729.0 & 27 & 90.3 & 26 & 200.0 \\
\hline & 10.3 & -2.42 & 0.087 & 0.08 & 0.003 & 2169.0 & 27 & 293.5 & 26 & 396.4 \\
\hline & 12.5 & -3.80 & 0.166 & 0.13 & 0.006 & 1442.0 & 19 & 75.2 & 18 & 143.5 \\
\hline & 16.0 & -2.24 & 0.134 & 0.09 & 0.004 & 1093.0 & 19 & 185.5 & 18 & 255.8 \\
\hline & 19.2 & -2.04 & 0.105 & 0.08 & 0.003 & 1725.0 & 24 & 229.2 & 23 & 416.3 \\
\hline & 22.8 & -3.44 & 0.181 & 0.12 & 0.006 & 1198.0 & 15 & 86.1 & 14 & 136.5 \\
\hline & 26.2 & -1.67 & 0.123 & 0.06 & 0.003 & 919.4 & 18 & 155.6 & 17 & 217.8 \\
\hline & 28.7 & -2.97 & 0.191 & 0.11 & 0.007 & 674.9 & 9 & 60.3 & 8 & 96.1 \\
\hline & 29.8 & -2.06 & 0.156 & 0.07 & 0.004 & 622.1 & 10 & 113.1 & 9 & 152.1 \\
\hline & 30.5 & -3.75 & 0.258 & 0.12 & 0.008 & 437.0 & 6 & 22.6 & 5 & 49.7 \\
\hline & 33.7 & -3.44 & 0.170 & 0.13 & 0.006 & 989.1 & 14 & 10.6 & 13 & 67.9 \\
\hline \multirow[t]{12}{*}{ Broad bean } & 3.8 & -3.55 & 0.111 & 0.07 & 0.002 & 1590.4 & 24 & 36.7 & 23 & 131.8 \\
\hline & 7.4 & -3.60 & 0.156 & 0.08 & 0.003 & 1280.0 & 19 & 75.1 & 18 & 152.0 \\
\hline & 10.5 & -3.55 & 0.153 & 0.08 & 0.003 & 1561.0 & 22 & 107.0 & 21 & 185.8 \\
\hline & 13.9 & -4.34 & 0.182 & 0.10 & 0.004 & 959.3 & 14 & 50.1 & 13 & 108.6 \\
\hline & 17.5 & -2.80 & 0.128 & 0.06 & 0.003 & 1164.7 & 19 & 97.7 & 18 & 174.1 \\
\hline & 20.6 & -2.71 & 0.127 & 0.05 & 0.002 & 974.0 & 17 & 80.1 & 16 & 153.4 \\
\hline & 24.0 & -1.86 & 0.110 & 0.04 & 0.002 & 923.4 & 20 & 117.9 & 19 & 199.6 \\
\hline & 25.3 & -3.07 & 0.142 & 0.06 & 0.003 & 1273.5 & 15 & 99.1 & 14 & 155.7 \\
\hline & 25.8 & -2.58 & 0.126 & 0.04 & 0.002 & 1040.0 & 16 & 54.9 & 15 & 119.6 \\
\hline & 27.2 & -2.38 & 0.098 & 0.03 & 0.001 & 1048.0 & 19 & 120.8 & 18 & 204.3 \\
\hline & 29.6 & -2.05 & 0.091 & 0.03 & 0.001 & 1206.9 & 19 & 81.0 & 18 & 160.3 \\
\hline & 31.4 & -3.15 & 0.125 & 0.07 & 0.003 & 1186.0 & 17 & 34.6 & 16 & 104.2 \\
\hline \multirow[t]{14}{*}{ Corn } & 11.1 & -4.06 & 0.170 & 0.28 & 0.012 & 977.8 & 15 & 22.9 & 14 & 85.6 \\
\hline & 13.8 & -5.39 & 0.237 & 0.29 & 0.013 & 922.0 & 13 & 17.1 & 12 & 70.1 \\
\hline & 17.3 & -4.45 & 0.187 & 0.20 & 0.008 & 1412.2 & 17 & 31.2 & 16 & 94.8 \\
\hline & 20.2 & -6.35 & 0.335 & 0.31 & 0.016 & 912.5 & 10 & 11.4 & 9 & 49.5 \\
\hline & 23.4 & -4.63 & 0.335 & 0.24 & 0.016 & 611.1 & 8 & 20.6 & 7 & 53.7 \\
\hline & 26.9 & -4.80 & 0.308 & 0.25 & 0.016 & 489.8 & 6 & 16.2 & 5 & 42.5 \\
\hline & 30.7 & -3.82 & 0.272 & 0.19 & 0.012 & 572.9 & 8 & 45.8 & 7 & 75.6 \\
\hline & 31.6 & -4.72 & 0.345 & 0.24 & 0.018 & 588.7 & 6 & 19.1 & 5 & 41.1 \\
\hline & 32.7 & -5.40 & 0.400 & 0.28 & 0.020 & 602.8 & 6 & 28.7 & 5 & 50.7 \\
\hline & 34.4 & -3.51 & 0.257 & 0.15 & 0.010 & 535.7 & 8 & 50.5 & 7 & 80.3 \\
\hline & 36.2 & -3.37 & 0.197 & 0.12 & 0.007 & 667.3 & 9 & 21.9 & 8 & 58.2 \\
\hline & 38.3 & -2.66 & 0.169 & 0.12 & 0.007 & 518.2 & 10 & 49.6 & 9 & 94.0 \\
\hline & 38.7 & -2.19 & 0.163 & 0.10 & 0.007 & 494.0 & 9 & 58.7 & 8 & 99.4 \\
\hline & 40.1 & -2.98 & 0.213 & 0.20 & 0.014 & 362.9 & 7 & 40.3 & 6 & 73.7 \\
\hline \multirow[t]{14}{*}{ Sorghum } & 10.1 & -4.55 & 0.196 & 0.86 & 0.038 & 1047.0 & 15 & 89.5 & 14 & 151.6 \\
\hline & 13.8 & -3.28 & 0.169 & 0.23 & 0.011 & 968.3 & 17 & 79.3 & 16 & 147.1 \\
\hline & 16.4 & -2.67 & 0.149 & 0.18 & 0.009 & 903.0 & 16 & 99.3 & 15 & 163.6 \\
\hline & 19.7 & -3.34 & 0.175 & 0.21 & 0.010 & 1007.0 & 14 & 64.0 & 13 & 116.3 \\
\hline & 22.7 & -2.41 & 0.141 & 0.17 & 0.009 & 1039.0 & 15 & 105.5 & 14 & 157.3 \\
\hline & 26.7 & -2.80 & 0.196 & 0.19 & 0.012 & 603.1 & 9 & 45.1 & 8 & 79.0 \\
\hline & 28.5 & -3.65 & 0.243 & 0.27 & 0.018 & 513.0 & 6 & 18.5 & 5 & 43.7 \\
\hline & 31.3 & -1.76 & 0.159 & 0.13 & 0.009 & 590.8 & 9 & 119.9 & 8 & 153.3 \\
\hline & 33.6 & -2.93 & 0.231 & 0.20 & 0.014 & 447.4 & 6 & 56.2 & 5 & 80.8 \\
\hline & 34.3 & -1.68 & 0.136 & 0.11 & 0.008 & 563.9 & 9 & 99.8 & 8 & 136.7 \\
\hline & 36.6 & -1.19 & 0.146 & 0.07 & 0.007 & 479.1 & 8 & 152.7 & 7 & 185.7 \\
\hline & 39.1 & -1.68 & 0.111 & 0.11 & 0.006 & 751.1 & 11 & 133.8 & 10 & 178.5 \\
\hline & 40.5 & -2.40 & 0.168 & 0.18 & 0.012 & 562.4 & 8 & 49.3 & 7 & 82.9 \\
\hline & 42.1 & -2.72 & 0.171 & 0.18 & 0.010 & 539.5 & 9 & 39.7 & 8 & 80.0 \\
\hline
\end{tabular}



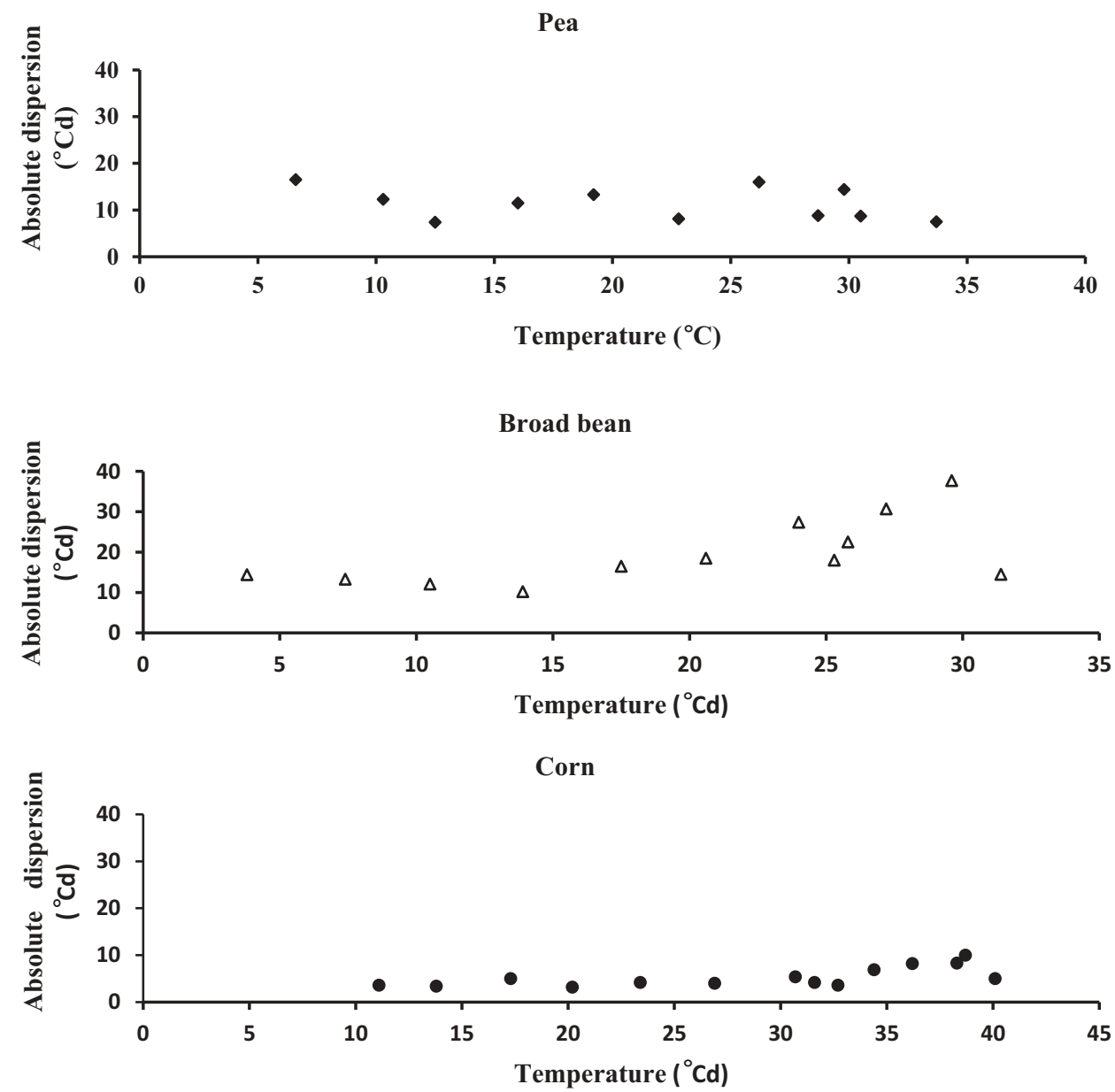

Sorghum

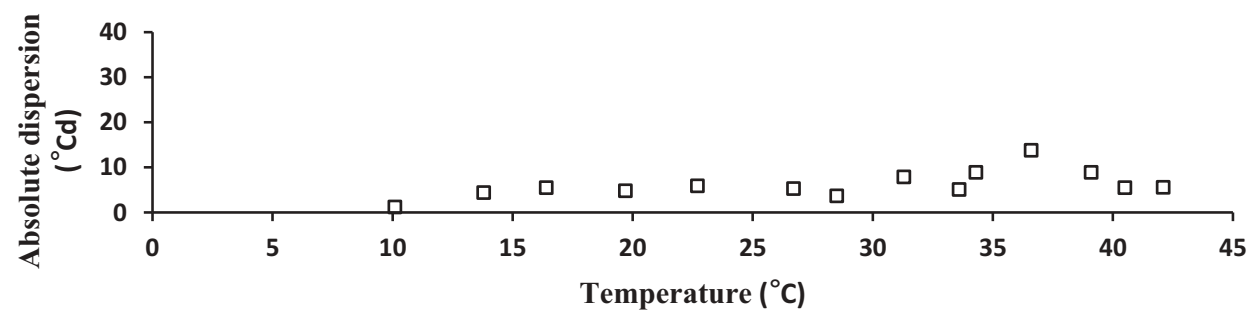

Figure 3. Absolute dispersion $\left(\sigma\right.$, in ${ }^{\circ} \mathrm{Cd}$ ) of pea $\bullet$, broad bean $\Delta$, corn $\bullet$, and sorghum $\square$, as a function of temperature.

optimal ranges) and to decrease again for temperatures above $\mathrm{T}_{\mathrm{o} 2}$. Values of $\sigma$ for winter crops also tended to increase at temperatures close to the base temperature (markedly in the case of the pea, more gently in the case of broad bean). Absolute dispersion values for pea were always $\geq 7^{\circ} \mathrm{Cd}$, whereas the minimum value observed for the dispersion of broad bean was around 
Table 6. Parameters from the probit regression used to evaluate the spread of germination as a function of temperature (T), for pea, broad bean, corn and sorghum: the most likely values of $\theta(\mu)$, estimates (est.) of absolute $(\sigma)$ and relative dispersion $\left(\mathrm{CV}_{\theta}\right)$ and corresponding $96 \%$ confidence intervals (c.i.).

\begin{tabular}{|c|c|c|c|c|c|c|}
\hline \multirow[b]{2}{*}{ Crop } & \multirow{2}{*}{$\frac{\text { Temperatures }}{\left({ }^{\circ} \mathrm{C}\right)}$} & \multirow{2}{*}{$\frac{\text { Most likely }}{\mu \text { value }\left({ }^{\circ} \mathrm{Cd}\right)}$} & \multicolumn{2}{|c|}{ Absolute dispersion $(\sigma)$} & \multicolumn{2}{|r|}{ Relative dispersion $\left(\mathrm{CV}_{\theta}\right)$} \\
\hline & & & est. $\left({ }^{\circ} \mathrm{Cd}\right)$ & $95 \%$ c.i. $\left({ }^{\circ} \mathrm{Cd}\right)$ & est. & Confidence intervals (95\%) \\
\hline \multirow[t]{11}{*}{ Pea } & 6.6 & 35.5 & 16.5 & [15.50. 17.59] & 0.46 & {$[0.44 .0 .49]$} \\
\hline & 10.3 & 29.8 & 12.3 & [11.57. 13.16] & 0.41 & {$[0.39 .0 .44]$} \\
\hline & 12.5 & 28.2 & 7.4 & [6.84. 8.05] & 0.26 & {$[0.24 .0 .29]$} \\
\hline & 16.0 & 25.8 & 11.5 & [10.54. 12.64] & 0.45 & {$[0.40 .0 .50]$} \\
\hline & 19.2 & 27.2 & 13.3 & [12.33. 14.43] & 0.49 & {$[0.45 .0 .54]$} \\
\hline & 22.8 & 28.0 & 8.1 & [7.42. 8.93] & 0.29 & {$[0.26 .0 .32]$} \\
\hline & 26.2 & 26.7 & 16.0 & [14.54. 17.75] & 0.60 & {$[0.53 .0 .70]$} \\
\hline & 28.7 & 26.2 & 8.8 & [7.88. 9.89] & 0.34 & {$[0.30 .0 .38]$} \\
\hline & 29.8 & 29.7 & 14.4 & [12.90.16.24] & 0.48 & {$[0.42 .0 .57]$} \\
\hline & 30.5 & 32.4 & 8.7 & [7.59. 9.95] & 0.27 & {$[0.23,0.31]$} \\
\hline & 33.7 & 25.8 & 7.5 & [6.88. 8.24] & 0.29 & {$[0.26 .0 .32]$} \\
\hline \multirow[t]{12}{*}{ Broad bean } & 3.8 & 51.1 & 14.4 & [13.55. 15.35] & 0.28 & {$[0.27 .0 .30]$} \\
\hline & 7.4 & 47.8 & 13.3 & [12.25. 14.43] & 0.28 & {$[0.26 .0 .30]$} \\
\hline & 10.5 & 42.9 & 12.1 & [11.21. 13.09] & 0.28 & {$[0.26 .0 .31]$} \\
\hline & 13.9 & 44.4 & 10.2 & {$[9.45 .11 .15]$} & 0.23 & {$[0.21 .0 .25]$} \\
\hline & 17.5 & 46.1 & 16.5 & [15.21.17.89] & 0.36 & [0.33. 0.39$]$ \\
\hline & 20.6 & 50.3 & 18.5 & [17.10. 20.19] & 0.37 & [0.34. 0.41$]$ \\
\hline & 24.0 & 50.8 & 27.4 & [25.07. 30.05] & 0.54 & [0.48. 0.61$]$ \\
\hline & 25.3 & 55.3 & 18.0 & [16.49.19.73] & 0.33 & {$[0.30 .0 .36]$} \\
\hline & 25.8 & 58.1 & 22.5 & [20.65. 24.58] & 0.39 & {$[0.35 .0 .43]$} \\
\hline & 27.2 & 73.1 & 30.7 & {$[28.51 .33 .26]$} & 0.42 & [0.39. 0.46$]$ \\
\hline & 29.6 & 77.3 & 37.7 & [34.89. 40.78] & 0.49 & {$[0.45 .0 .53]$} \\
\hline & 31.4 & 45.7 & 14.5 & [13.46. 15.67] & 0.32 & {$[0.29 .0 .34]$} \\
\hline \multirow[t]{14}{*}{ Corn } & 11.1 & 14.5 & 3.6 & [3.28. 3.89] & 0.25 & {$[0.23,0.27]$} \\
\hline & 13.8 & 18.5 & 3.4 & [3.14. 3.74] & 0.19 & [0.17. 0.20$]$ \\
\hline & 17.3 & 22.2 & 5.0 & [4.60. 5.41] & 0.22 & {$[0.21 .0 .24]$} \\
\hline & 20.2 & 20.3 & 3.2 & [2.89. 3.55] & 0.16 & [0.14. 0.17$]$ \\
\hline & 23.4 & 19.3 & 4.2 & [3.74. 4.66] & 0.22 & [0.19. 0.24$]$ \\
\hline & 26.9 & 19.3 & 4.0 & [3.56. 4.55] & 0.21 & {$[0.18 .0 .24]$} \\
\hline & 30.7 & 20.6 & 5.4 & [4.77. 6.15] & 0.26 & {$[0.23 .0 .30]$} \\
\hline & 31.6 & 19.7 & 4.2 & [3.63. 4.85] & 0.21 & {$[0.18 .0 .25]$} \\
\hline & 32.7 & 19.2 & 3.6 & [3.11. 4.10] & 0.19 & {$[0.16 .0 .21]$} \\
\hline & 34.4 & 24.1 & 6.9 & [6.05. 7.84] & 0.28 & {$[0.25 .0 .33]$} \\
\hline & 36.2 & 27.5 & 8.2 & [7.36. 9.13] & 0.30 & [0.27. 0.33$]$ \\
\hline & 38.3 & 22.1 & 8.3 & [7.50. 9.32] & 0.38 & [0.33. 0.43$]$ \\
\hline & 38.7 & 21.8 & 10.0 & [8.75. 11.43] & 0.46 & [0.40. 0.53$]$ \\
\hline & 40.1 & 15.0 & 5.0 & [4.37. 5.84] & 0.34 & [0.29. 0.39] \\
\hline \multirow[t]{14}{*}{ Sorghum } & 10.1 & 5.3 & 1.2 & [1.07. 1.27] & 0.22 & {$[0.20 .0 .24]$} \\
\hline & 13.8 & 14.3 & 4.4 & [4.00, 4.78] & 0.31 & {$[0.28,0.34]$} \\
\hline & 16.4 & 14.8 & 5.5 & [5.05. 6.09] & 0.37 & [0.34. 0.42$]$ \\
\hline & 19.7 & 16.1 & 4.8 & {$[4.40,5.30]$} & 0.30 & {$[0.27,0.33]$} \\
\hline & 22.7 & 14.2 & 5.9 & [5.37. 6.50] & 0.42 & [0.37. 0.47] \\
\hline & 26.7 & 14.8 & 5.3 & [4.70. 5.97] & 0.36 & [0.31. 0.41$]$ \\
\hline & 28.5 & 13.4 & 3.7 & [3.25. 4.19] & 0.27 & {$[0.24 .0 .31]$} \\
\hline & 31.3 & 13.9 & 7.9 & [6.98. 9.08] & 0.57 & [0.49. 0.68$]$ \\
\hline & 33.6 & 14.9 & 5.1 & [4.44. 5.88] & 0.34 & [0.29. 0.40] \\
\hline & 34.3 & 15.0 & 8.9 & [7.90. 10.18] & 0.60 & [0.51. 0.71] \\
\hline & 36.6 & 16.5 & 13.8 & [11.97. 16.31] & 0.84 & [0.69. 1.07] \\
\hline & 39.1 & 15.0 & 8.9 & [8.04. 9.95] & 0.59 & [0.53. 0.68$]$ \\
\hline & 40.5 & 13.1 & 5.5 & {$[4.86 .6 .22]$} & 0.42 & {$[0.37 .0 .48]$} \\
\hline & 42.1 & 15.3 & 5.6 & {$[5.05 .6 .34]$} & 0.37 & {$[0.33 .0 .42]$} \\
\hline
\end{tabular}


$10^{\circ} \mathrm{Cd}$. Dispersion values lower than $5^{\circ} \mathrm{Cd}$ were frequent across a wide range of temperatures for corn (from $11.1^{\circ} \mathrm{C}$ to $32.7^{\circ} \mathrm{C}$ ) and sorghum (from $10.1^{\circ} \mathrm{C}$ to $28.5^{\circ} \mathrm{C}$ ). Despite the differences found, no trend could be fitted to the sequence of data obtained for any of the crops studied. The calculated mean $\sigma$ values for the set of temperatures used for each crop were $11.3 \pm 3.42^{\circ} \mathrm{Cd}$ (pea), $19.7 \pm 8.36^{\circ} \mathrm{Cd}$ (broad bean), $5.3 \pm 2.14^{\circ} \mathrm{Cd}$ (corn) and $6.2 \pm 2.99^{\circ} \mathrm{Cd}$ (sorghum). These mean values were always lower than the value of $\sigma$ for the entire thermal-tolerance ranges (none of them belong to the corresponding 95\% confidence intervals) (Table 4). Relevant differences were also found between the average values of winter crops and those of summer crops, and also within individual winter crops.

Also, $\mathrm{CV}_{\theta}$ did not show any defined trend along the temperature range studied (Table 6). Values of $\mathrm{CV}_{\theta}$ ranged from $0.26\left(12.5^{\circ} \mathrm{C}\right)$ to $0.60\left(26.2^{\circ} \mathrm{C}\right)$ for pea, from $0.23\left(13.9^{\circ} \mathrm{C}\right)$ to $0.54\left(24.0^{\circ} \mathrm{C}\right)$ for broad bean, from $0.16\left(20.2^{\circ}\right.$ C) to $0.46\left(28.7^{\circ} \mathrm{C}\right)$ for corn and from $0.22\left(10.1^{\circ} \mathrm{C}\right)$ to $0.59\left(39.1^{\circ} \mathrm{C}\right)$ for sorghum.

b) Dispersion expressed by $\theta_{0.8}-\theta_{0.2}$ and $t_{0.8}-t_{0.2}$.

For the different temperatures tested, the spread of germination, as measured by $\theta_{0.8}-\theta_{0.2}$, closely followed the corresponding variation of absolute dispersion $(\sigma)$ described above. The calculated mean values of $\theta_{0.8}-\theta_{0.2}$ for the set of temperatures used for pea, broad bean, corn, and sorghum were $3.4 \pm 7.19^{\circ} \mathrm{Cd}, 28.3 \pm 14.03^{\circ} \mathrm{Cd}, 9.3 \pm 3.62^{\circ} \mathrm{Cd}$, and $7.4 \pm 2.58^{\circ} \mathrm{Cd}$, respectively. Average values of $\theta_{0.8}-\theta_{0.2}$ for each crop were lower than the corresponding values of $2 \sigma$ (which corresponds with $\pm 34.1 \%$ of the germinations around the mean value of thermal time). These differences ranged from $1.4^{\circ} \mathrm{Cd}$ (corn) to about $11^{\circ} \mathrm{Cd}$ (broad bean). Also, the values for individual temperature were often lower than $2 \sigma$ values, with the mean of the differences of the paired dispersions ranging from $2.1^{\circ} \mathrm{Cd}$ (pea) to $9.1^{\circ} \mathrm{Cd}$ (broad bean). A strong linear relation $\left(\mathrm{R}^{2}=0.83\right.$, in a regression where $\left.\mathrm{P}<0.0001\right)$ was found when $\sigma$ values estimated for all the temperatures and crops used in the experiments were plotted against the corresponding $\theta_{0.8}-\theta_{0.2}$ values (Figure 4). This successful fit provides estimates of the absolute dispersion (sigma) from the values of $\theta_{0.8}-\theta_{0.2}$.

When measured by $t_{0.8}-t_{0.2}$, the spread of germination as a function of temperature followed a U-shaped pattern for all crops (Figure 5). Along a fairly broad thermal range, the spread was close to its minimum value (about $9 \mathrm{~h}$ for corn and sorghum, 10.4 and $29.7 \mathrm{~h}$ for pea and broad bean, respectively), but it tended to increase close to the extreme temperatures tested (much more pronounced for the lowest temperatures tested than for the highest). For temperatures close to $T_{b}$, pea and broad bean spreads $t_{0.8}-t_{0.2}$ were slightly lower than $200 \mathrm{~h}$, whereas corn and sorghum had spreads of around 80 and $55 \mathrm{~h}$, respectively. In the highest temperature range, the values of $t_{0.8}-t_{0.2}$ 


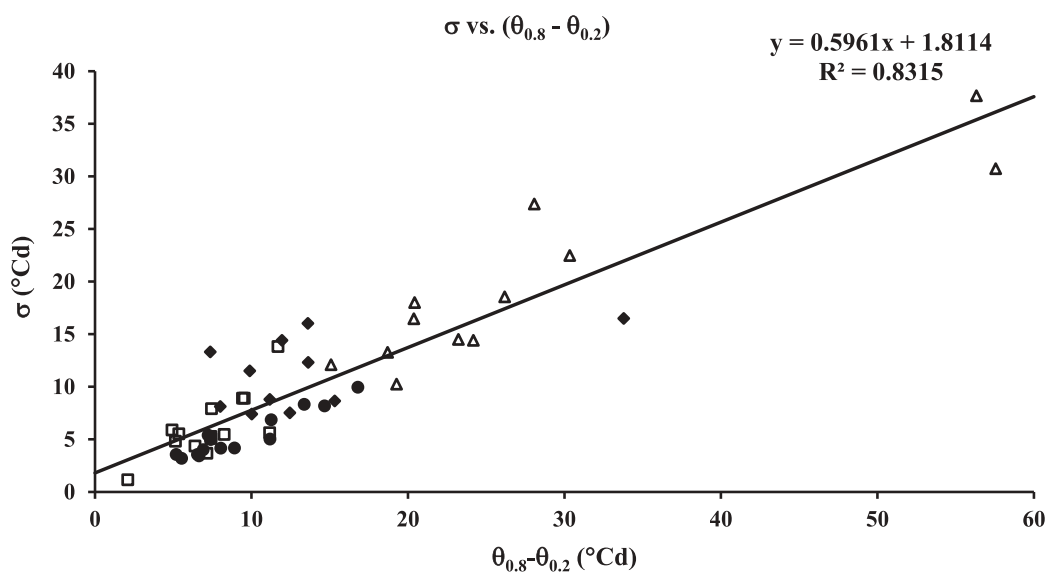

Figure 4. Relationship between $\sigma$ and $\left(\theta_{0.8}-\theta_{0.2}\right)$ values, for pea $\bullet$, broad bean $\Delta$, corn $\bullet$, and sorghum $\square$.

ranged from $20 \mathrm{~h}$ (sorghum) to $39 \mathrm{~h}$ (broad bean). For all crops, the temperatures where $t_{0.8}-t_{0.2}$ increases belong to the supraoptimal range (Table 1).

Based on the observed U-shaped pattern of the relationship between $\mathrm{t}_{0.8}$ $\mathrm{t}_{0.2}$ and temperature, an empirical model was fitted to describe the underlying trend in that relation. The model is the following polynomial function of even degree:

$$
f_{k}(T)=D_{\min }+\left(\frac{T-T_{\min }}{c}\right)^{2 k}(\text { hours })
$$

where $\mathrm{k}(=\{1,2,3, \ldots\})$ is an integer parameter controlling the size of the interval with the flattened out portion, close to the minimum of the function; $\mathrm{D}_{\text {min }}$ is the minimum value of $\mathrm{t}_{0.8} \mathrm{t}_{0.2}$ (minimum dispersion, in hours); $\mathrm{T}_{\text {min }}$ (in ${ }^{\circ} \mathrm{C}$ ) is the central (midpoint) value of temperatures in the range corresponding to the base around $\mathrm{D}_{\min }$; and $\mathrm{c}$ (in ${ }^{\circ} \mathrm{C}$ ) is a parameter associated with the width of that base. For any given value of $k$, this model was fitted using standard non-linear regression procedures.

Estimates of $\mathrm{D}_{\min }, \mathrm{T}_{\min }$ and $\mathrm{c}$ and measures of goodness-of-fit are shown in Table 7. Best fits were obtained with polynomials of degree $2 \mathrm{k}=6$ for broad been and pea, and of degree $2 k=4$ for the summer crops. Adequacy measures (residual sum of squares and AIC) are generally good for all crops, although better for pea and sorghum than for broad bean and corn. Values of $D_{\text {min }}$, $\mathrm{T}_{\text {min, }}$ and the length of the thermal plateau that ensures minimum levels of dispersion for germination, depend on the type of crop. In the context of these solutions, broad bean presented considerably larger values of $D_{\min }(\approx 30 \mathrm{~h})$ than those of the other crops (around 9-10 h). All $\mathrm{T}_{\min }$ values were different from each other (their 95\% confidence intervals do not overlap) and naturally higher in the case of summer crops. 

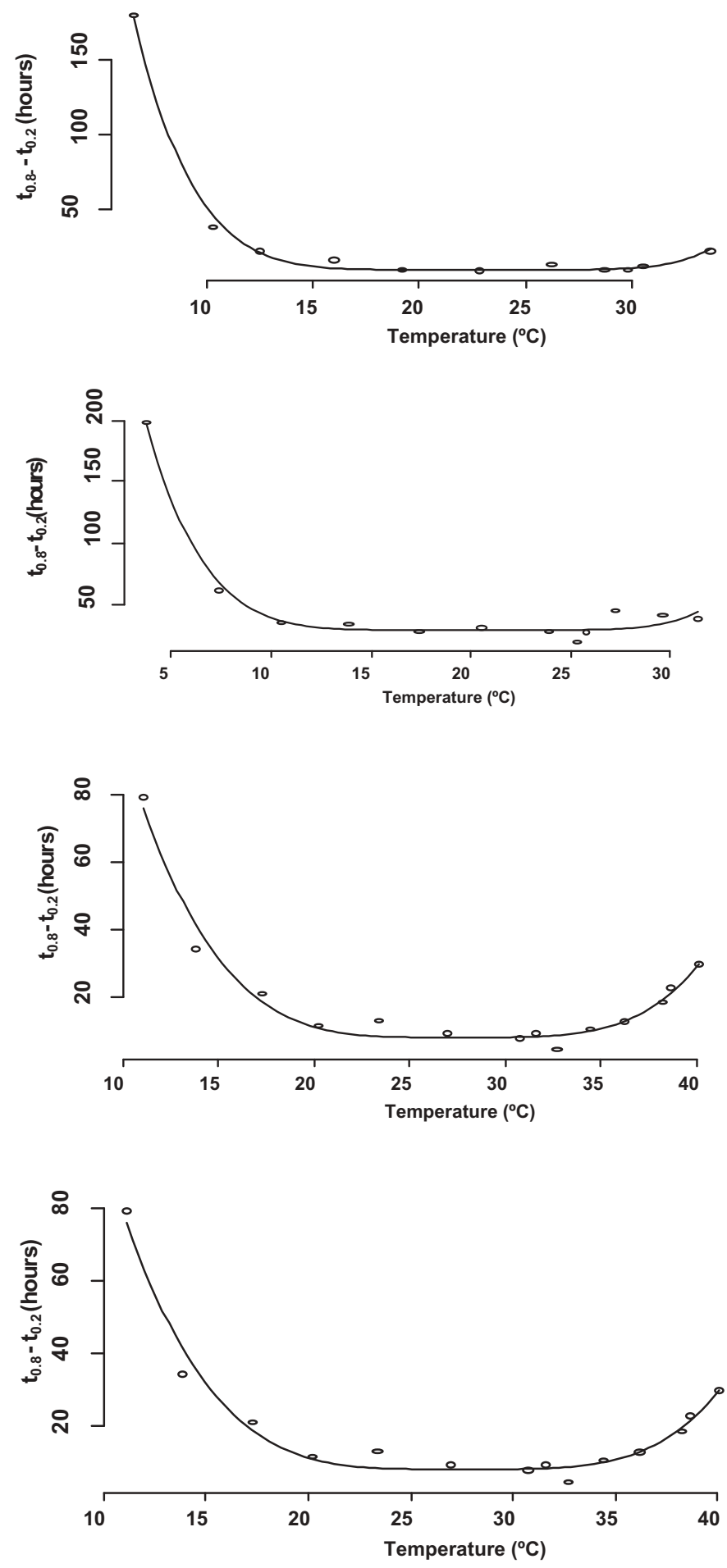

Figure 5. Dispersion of germination (expressed by $t_{0.8}-t_{0.2}$ ) vs. Temperature, for pea, broad bean, corn, and sorghum. 
Table 7. Parameters estimated from the polynomial model used to simulate dispersion of germination (expressed as $t_{0.8} t_{0.2}$ ) as a function of temperature (Eq. 7), for pea, broad bean, corn, and sorghum: $k$ (shape parameter); estimates (est.) of $D_{\min }$ (minimal dispersion), $T_{\min }$ (the central point of the plateau) and c (extent of the plateau) and corresponding $95 \%$ confidence intervals (c.i.), RSS (residual sum-of-squares) and AIC (Akaike Information Criterion).

\begin{tabular}{|c|c|c|c|c|c|c|c|c|c|}
\hline \multirow[b]{2}{*}{ Crop } & \multirow[b]{2}{*}{ k } & \multicolumn{2}{|c|}{$D_{\min }$ (hours) } & \multicolumn{2}{|r|}{$\mathrm{T}_{\min }\left({ }^{\circ} \mathrm{C}\right)$} & \multicolumn{2}{|r|}{$c\left({ }^{\circ} \mathrm{C}\right)$} & \multirow[b]{2}{*}{ RSS } & \multirow[b]{2}{*}{ AIC } \\
\hline & & est. & 95\% c.i. & est. & 95\% c.i. & est. & 95\% c.i. & & \\
\hline Pea & 3 & 10.4 & [7.55. 13.16] & 22.9 & [22.42. 23.64] & 6.9 & [6.73. 7.27] & 103.2 & 63.8 \\
\hline Broad bean & 3 & 29.7 & [24.47. 34.83] & 20.4 & [19.58, 22.23] & 7.1 & [6.70. 7.89] & 443.0 & 85.4 \\
\hline Corn & 2 & 8.7 & [6.35. 11.06] & 27.7 & [27.24. 28.17] & 5.8 & [5.59. 6.02] & 104.8 & 75.9 \\
\hline Sorghum & 2 & 8.8 & [7.46. 10.15] & 29.4 & [28.75. 30.24] & -7.3 & {$[-7.05,-7.73]$} & 38.4 & 61.9 \\
\hline
\end{tabular}

The intersection of each polynomial function (Equation 7), with horizontal lines representing a certain acceptable level of dispersion, provided two temperatures delimiting a thermal band along which the dispersion is minimal. For example, if an increase of $1 \%$ in the minimum value estimated for the dispersion $\left(1.01 \mathrm{D}_{\mathrm{min}}\right)$ is considered a maximum acceptable level for the dispersion, broad bean and pea (both fitted with $\mathrm{k}=3$ ) presented the widest plateaus (with length $11.3^{\circ} \mathrm{C}$ and $9.6^{\circ} \mathrm{C}$, respectively), whereas the summer crops (both fitted with $\mathrm{k}=2$ ) presented the narrowest $\left(6.4^{\circ} \mathrm{C}\right.$ and $8.0^{\circ} \mathrm{C}$ for corn and sorghum, respectively). According to the $\mathrm{T}_{\text {min }}$ values obtained, the plateaus estimated for a dispersion $1.01 \mathrm{D}_{\min }$ correspond to the following thermal ranges $\left(\right.$ in ${ }^{\circ} \mathrm{C}$ ): [18.1, 27.7] for pea; $[14.8,26.1]$ for broad bean; $[24.5,30.9]$ for corn; and [25.4, 33.4] for sorghum. These thermal ranges (hereafter expressed by $\left[\mathrm{T}_{\mathrm{o} 1} \mathrm{sd}, \mathrm{T}_{\mathrm{o} 2} \mathrm{sd}\right]$ ) provide, in any case, the smallest dispersion values, and represent a considerable shortening of the thermal tolerance-range of each crop.

\section{Discussion}

The results obtained show that it is possible to obtain different dispersion values for crop germination, depending on the methodology used. Dispersion values could be assigned not only to the thermal-tolerance range of each crop studied but also to the different thermal sub-ranges and to single temperatures.

The probit model (Equation 1) was successfully used to estimate dispersion values, expressed as the standard deviation $(\sigma)$ of the frequency distribution of thermal times in the population, either for a thermal range or for single temperatures. The spread of germination, expressed as $\mathrm{t}_{0.8} \mathrm{t}_{0.2}$, as a function of temperature can be successfully described by a polynomial function (Equation 7), allowing the definition of a thermal range that guarantees minimum values of dispersion ([ $\left.\mathrm{T}_{\mathrm{o} 1} \mathrm{sd}, \mathrm{T}_{\mathrm{o} 2} \mathrm{sd}\right]$ ).

When used to characterize the dispersion in the different thermal ranges, $\sigma$ values provided a valid criterion to assess the adaptability of each crop to different climates (in permanent change) and soil water and, in particular, to assist in choosing between them under given conditions. If used to assign dispersion 
values for single temperatures, it provides further relevant information, namely for decisions regarding sowing times. Similar information could be found when other dispersion indicators to assess the dispersion at each temperature, expressed in ${ }^{\circ} \mathrm{Cd}\left(\theta_{0.8}-\theta_{0.2}\right)$ or in days or hours $\left(\mathrm{t}_{0.8}-\mathrm{t}_{0.2}\right)$, were used.

Despite the statistical validity of the results obtained for the different thermal ranges, their practical usefulness grows with their goodness-of-fit. Whenever the lowest temperatures were not considered (narrow suboptimal range), the goodness-of-fit of the probit model improved, whereas the dispersion (both absolute and relative) values decreased. These differences (with statistical significance in 3 out of 4 cases) are likely to be attributable to the lower goodness-of-fit of the linear model between rate and temperature at low temperatures, where the rate is usually underestimated (Hsu, Nelson, and Chow 1984; Marshall and Squire 1996). This may result from greater sensitivity of germination times to small variations of temperatures close to $\mathrm{T}_{\mathrm{b}}$ (Covell et al. 1986), smaller final percentages of germination below a.a.m. in some cases (Andrade 2001) or even (very common) measurement errors at the lowest temperatures (Garcia-Huidobro, Monteith, and Squire 1982; Ducournau et al. 2005). Therefore, there is no substantive reason for not consider the narrow instead of the broad suboptimal range, when characterizing the dispersion below $\mathrm{T}_{\mathrm{o} 1}$.

The accumulated temperature increases along the thermal range where germination rate is constant (i.e., further increases in temperature make little difference for the germination process). As dispersion depends on accumulated temperature, the estimated values $(\sigma)$ for the optimal range were generally greater than those for the other ranges (only for pea was $\sigma$ value lower, although the differences were not significant); the goodness of fits worsened in most cases. In short, the fastest germinations do not necessarily correspond to the least dispersed germinations. Future work in modeling germination should pay special attention to the differences between $\sigma$ values for the optimal range and those of other ranges for two main reasons: (a) $\sigma$ increased (Table 4) with the extension of the optimal range (Table1) and (b) part of the optimum range is included in the interval $\left[\mathrm{T}_{\mathrm{o} 1} \mathrm{sd}, \mathrm{T}_{\mathrm{o} 2} \mathrm{sd}\right]$.

Finally, the estimated absolute dispersion values for the supraoptimal range are considerably smaller than those obtained for the remaining subranges (suboptimal and optimal ranges). In this case, the goodness of fit of the probit model improved for the winter crops only. The differences in $\sigma$ values are attributable to the different extensions of the suboptimal and supraoptimal ranges $\left(\mathrm{T}_{\mathrm{o} 1}-\mathrm{T}_{\mathrm{b}} \gg \mathrm{T}_{\mathrm{c}}-\mathrm{T}_{\mathrm{o} 2}\right.$ in most cases). The relevance for the study of the dispersion of this sub-range depends on the relative position between $T_{02}$ and the upper limit of the thermal range that guarantees minimum values of dispersion $\left(\mathrm{T}_{\mathrm{o} 2} \mathrm{sd}\right)$. As no intersection was found between the supraoptimal ranges and the corresponding $\left[\mathrm{T}_{\mathrm{o} 1} \mathrm{sd}, \mathrm{T}_{\mathrm{o} 2} \mathrm{sd}\right]$ ranges for 
these four crops, the practical importance of the supraoptimal range in agronomic choices is minimized when compared with the other sub-ranges.

Evaluating how dispersion varies with temperature from $T_{b}$ to $T_{c}$ was another goal. Under non-limiting water conditions, no trend was found for the sequence of $\theta_{0.8}-\theta_{0.2}$ and $\sigma$ values that were obtained for any of the crops studied. However, the shape of the function used to model the variation of $\mathrm{t}_{0.8}-\mathrm{t}_{0.2}$ with temperature (Figure 5) is similar to that of the time course of germination as a function of temperature for any germinated fraction (Olivier and Annadale 1998; Nori, Moot, and Black 2014), i.e., the dispersion expressed by $t_{0 .} 8^{-t_{0.2}}$ is close to minimum values across a relatively wide thermal range and increases at both ends. However, the increases of $\mathrm{t}_{0.8}-\mathrm{t}_{0.2}$ at both thermal extremes did not have the same magnitude (they were greater in the cold end), nor may they be justified in the same way. The larger dispersions observed at temperatures near the base temperature lead to a longer residence time of the seeds in the soil, thus risking final germinations below a.a.m. (as in the cases of pea and broad bean). At the other end (supraoptimal range), the higher the temperature, the faster the abrupt interruption of the germination process of a seed population (with consequent decrease in $\mathrm{G}_{\mathrm{f}}$ ), thereby attenuating the expected increase in dispersion (attributable either to temperature or to the S-shaped curve), as a direct result of the cumulative germination curve cracking.

In spite of its undeniable usefulness (Trudgill et al. 2005), the use of the thermal time as the predictor variable was less effective in situations where extreme temperatures or the difficulty in controlling factors, such as availability in water, become limiting factors because they can increase excessively the time of permanence of the seeds in the soil (with the eventual drying of the pre-moistened seed or decay). As thermal time accommodates by definition the effects of temperature or chronological time on the rates of development of any process, possible deleterious effects of chronological time on germination are not easily detectable at extreme temperatures (mainly at the lowest). In such situations, the use of chronological time, instead of thermal time, to predict the course of germination and therefore its dispersion may be preferable, providing a better definition of the thermal range that guarantees a minimum dispersion. In addition, dispersion values greater than $D_{\text {min }}$ (Table 7) suggest to the farmer that factors other than temperature (e.g., availability of water in the soil) are at work.

Those limiting conditions are especially relevant in areas with a Mediterranean climate, where the irregularity of rainfall leads to quick changes in soil water content and to periods of soil drying that are more frequent and longer than those of wetting, with likely drastic decreases in the final percentage of germinated seeds. When the dispersion was expressed as differences in germination time $\left(\mathrm{t}_{0.8}\right.$ $-\mathrm{t}_{0.2}$, in this case), a fairly long thermal range (but considerably smaller than the thermal-tolerance range of each crop) along which the dispersion has acceptably small values was identified. Using this thermal sub-range to choose the time of 
sowing, taking into account the weather forecast, may prevent excessive seed permanence in the soil. This thermal range depends on a prior definition of maximum acceptable levels for the dispersion of each crop, with values that may differ from region to region (similar to those considered for final germination size, as shown in Table 1). Minimum dispersion ranges are, together with intervals that guarantee a high percentage of germinated seeds and optimal speeds for the germination process, fundamental parameters to optimize the germination of a given crop.

How the results obtained can be used to evaluate the competitiveness of crops is another issue. The less time the seeds remain in the soil and the less dispersed their germination, the more competitive the crop will be. Three parameters can be examples of indicators of the crop competitiveness: first, values of $2 \sigma$ measure the (absolute) dispersion of $0.682 \mathrm{G}_{\mathrm{f}}$ around the mean thermal time value $(\mu)$; secondly, $(\mu+\sigma)$ values measure the accumulated temperature above $T_{b}$ needed to germinate $84.1 \%(50+34.1 \%)$ of seeds; finally, $\mathrm{CV}_{\theta}(=\sigma / \mu)$ improves the assessment of the germinative process by characterizing it as a function of the relationship between its speed and its (absolute) dispersion, helping us to understand absolute dispersion in the context of $\mu$. The application of these criteria to the dispersion behavior of the four crops under study led to different results. According to the first indicator $(2 \sigma)$, corn was the most competitive of the four crops, whereas broad bean was the least, if we stick to the suboptimal and optimum range only. If we consider the values obtained for the thermal-tolerance range, $68.2 \%(\mu \pm \sigma)$ of seeds of broad bean at $25^{\circ} \mathrm{C}$ took at least $47.2 \mathrm{~h}$ to germinate, whereas those of pea, sorghum, and corn took 23.0, 16.9, and $13.8 \mathrm{~h}$, respectively (Table 4). If the germination time up to $0.341 \mathrm{G}_{\mathrm{f}}$ is also taken into account (second indicator), sorghum becomes, for the same two ranges, more competitive than the other crops $\left(20.4^{\circ} \mathrm{Cd}\right.$ and $25.5^{\circ} \mathrm{Cd}$, respectively), whereas the two winter crops need to accumulate more temperature until reaching $0.841 \mathrm{G}_{\mathrm{f}}$. (e.g., broad bean, the less competitive, needs $60.4^{\circ} \mathrm{Cd}$ and $90.2^{\circ} \mathrm{Cd}$, respectively). Finally, corn presented the lowest $\mathrm{CV}_{\theta}$, aligning a relatively high germination speed to a very low dispersion along suboptimal and optimal ranges ( 0.21 and 0.33 , respectively), whereas sorghum presented the greatest $\mathrm{CV}_{\theta}(\approx 0.7$ in the sub-ranges considered), ensuring also a high germination speed but not as small a dispersion as corn. The winter crops had intermediate $\mathrm{CV}_{\theta}$ values (about 0.40 for pea and from 0.29 to 0.50 for broad bean). Differences between pea and broad bean or between corn and sorghum may have practical relevance because they are sown at the same time and develop favorably under similar agro-ecological conditions. According to the criterion to be evaluated in each situation (competitiveness based on residence time of the seeds $v s$. uniformity), the above-mentioned indicators may be chosen. 


\section{Conclusions}

Reference values may be determined for the germination dispersion of each crop. It is also possible to define, for each crop, a thermal range across which the dispersion of its germination is acceptably small. This allows farmers to improve the choice between crops according to the greater or lesser adaptability to the prevailing climatic conditions and, for each crop, to optimize the germination process. In this way, greater uniformity in the initial development of each culture, which is an indispensable prerequisite for its success, becomes an easier goal to achieve.

\section{Disclosure statement}

No potential conflict of interest was reported by the authors.

\section{Funding}

This first author was partially supported by ICAAM - Instituto de Ciências Agrárias e Ambientais Mediterrâneas. The second author was partially supported by the Portuguese Foundation for Science and Technology (FCT) through the project [UID/MAT/00006/2019].

\section{ORCID}

José A. Andrade (10) http://orcid.org/0000-0003-0233-4330

\section{References}

Abreu, F., and J. Clark. 1993. "Groundnut Seedling Emergence in Relation to Thermal-Time and Soil Water." Anais Instituto Superior Agronomia 43: 219-232.

Akaike, H. 1998. "Information Theory and an Extension of the Maximum Likelihood Principle." In Selected Papers of Hirotugu Akaike. Springer Series in Statistics (perspectives in Statistics), edited by E. Parzen, K. Tanabe, and G. Kitagawa, 267-281. New York (NY): Springer. doi:10.1007/978-1-4612-1694-0_15.

Andrade, J. 2001. Temperatura Do Solo (E Análise De Fourier), Humidade Do Solo E Desenvolvimento Inicial De Várias Culturas Em Solos Pmg E Cb. Dissertação Para Provas De Doutoramento. Évora (Portugal): Universidade de Évora.

Andrade, J., J. Cadima, and F. M. Abreu. 2018. "Modelling Germination Rate and Cardinal Temperatures of Seven Mediterranean Crops." Journal of Crop Improvement 32 (6): 878-902. doi:10.1080/15427528.2018.1542362.

Asomaning, J. M., M. Sacande, and N. S. Olympio. 2011. "Germination Responses of Terminalia Superba Engl. And Diels Seeds on the 2-way Grant's Thermogradient Plate." Research Journal of Seed Science 4 (1): 28-39. doi:10.3923/rjss.2011.28.39.

Bahler, C., R. R. Hill, and R. A. Byers. 1989. "Comparison of Logistic and Weibull Functions: the Effect of Temperature on Cumulative Germination of Alfafa." Crop Science 29: 142-146. doi:10.2135/cropsci1989.0011183X002900010032x. 
Bewley, J. D., and E. M. Black. 1994. Seeds. Physiology of Development and Germination. 2ed ed. New York and London: Plenum Press.

Carvalho, M. P., D. G. Santana, and M. A. Ranal. 2005. "Emergência De Plântulas De Anacardium Humile A. St.- Hil. (anacardiaceae) Avaliada Por Meio De Amostras Pequenas." Revista Brasileira De Botânica 28: 627-633.

Covell, S., R. H. Ellis, R. H. Roberts, and R. J. Summerfield. 1986. "The Influence of Temperature on Seed Germination Rate in Grain Legumes. I. A Comparison of Chickpea, Lentil, Soybean and Cowpea at Constant Temperatures." Journal of Experimental Botany 37: 705-715. doi:10.1093/jxb/37.5.705.

Ducournau, S., A. Feutry, P. Plainchault, P. Revollon, B. Vigouroux, and M. H. Wagner. 2005. "Using Computer Vision to Monitor Germination Time Course of Sunflower (helianthus Annuus L.) Seeds." Seed Science and Technology 33: 329-340. doi:10.15258/sst.

Ellis, R. H., G. Simon, and S. Covell. 1987. "The Influence of Temperature on Seed Germination Rate in Grain Legumes. III A Comparison of Five Faba Bean Genotypes at Constant Temperatures Using A New Screening Method." Journal of Experimental Botany 38: 1033-1043. doi:10.1093/jxb/38.6.1033.

Ferrão, A., and F. Abreu. 1996. "Placa De Gradiente Térmico Para Estudos De Germinação De Sementes a Temperaturas Constantes." Anais Instituto Superior Agronomia 45: 441-454.

Garcia-Huidobro, J., J. L. Monteith, and G. R. Squire. 1982. "Time, Temperature and Germination of Pearl Millet (pennisetum Typhoides S. And H). I. Constant Temperature." Journal of Experimental Botany 33: 288-296. doi:10.1093/jxb/33.2.288.

Hageseth, G. T., and A. L. Cody. 1993. "Energy-Level Model for Isothermal Seed Germination." Journal of Experimental Botany 44 (238): 119-125. doi:10.1093/jxb/44.1.119.

Hardegree, S. P. 2006. "Prediction Germination Response to Temperature I. Cardinal Temperature Models and Subpopulation-Specific Regression." Annals of Botany 97: 1115-1125. doi:10.1093/aob/mcl071.

Heidecker 1973. "Glossary of terms". In Seed Ecology, edited by W. Heidecker, 553-557. London (United Kingdom): Butterworths.

Hsu, F. H., C. J. Nelson, and W. S. Chow. 1984. "A Mathematical Model to Utilise the Logistic Function in Germination and Seedling Growth." Journal of Experimental Botany 35: 1629-1640. doi:10.1093/jxb/35.11.1629.

Kader, M. A. 2005. "A Comparison of Seed Germination Calculation Formulae and the Associated Interpretation of Resulting Data." Journal of Proceedings of the Royal Society of New South Wales 138: 65-75.

Marshall, B., and G. R. Squire. 1996. "Non-linearity in Rate-temperature Relations of Germination in Oilseed Rape." Journal of Experimental Botany 47: 1369-1375. doi:10.1093/jxb/47.9.1369.

McCullaugh, P., and J. A. Nelder. 1989. Generalized Linear Models. 2nd ed. London, UK: Chapman \& Hall/CRC.

McCulloch, C., S. R. Searle, and J. M. Neuhaus. 2008. Generalized, Linear, and Mixed Models. 2nd ed. New Jersey (USA): Wiley-Interscience.

Miguel, M. C. 1983. Métodos De Germinação De Sementes Das Espécies Mais Utilizadas Pela Agricultura Portuguesa. Oeiras (Portugal): Ministério da Agricultura, D.C.G.

Mohamed, H. A., J. L. Clark, and C. K. Ong. 1988. "Genotypic Differences in the Temperature Responses of Tropical Crops. I. Germination Characteristics of Groundnut (arachis Hypogea L.) And Pearl Millet (pennisetum Typhoides S.and H).” Journal of Experimental Botany 39: 1121-1128. doi:10.1093/jxb/39.8.1121.

Monteith, J. L. 1977. “Climate.” In Ecophisiology of Tropical Crops, edited by P. T. Alvin and T. T. Kozlowsky, 1-25. New York (USA): Academic Press. 
Nori, H., D. J. Moot, and A. D. Black. 2014. "Thermal Time Requirements for Germination of Four Annual Clover Species.” New Zealand Journal Agricultural Research 57 (1): 30-37. doi:10.1080/00288233.2013.863786.

Olivier, F. C., and J. G. Annadale. 1998. “Thermal Time Requirements for the Development of Green Ea (pisum Sativum, L.)." Field Crops Research 56: 301-307. doi:10.1016/S03784290(97)00097-X.

Piper, E. L., K. J. Boote, J. W. Jones, and S. S. Grimm. 1996. “Comparison of Two Phenology Models for Predicting Flowering and Maturity Date of Soybean." Crop Science 36: 1606-1614. doi:10.2135/cropsci1996.0011183X003600060033x.

Pourreza, J., and A. Bahrani. 2012. "Estimating Cardinal Temperatures of Milk Thistle (silybum Marianum) Seed Germination.” American-Eurasian Journal Agricultural Environmental Science 12 (11): 1485-1489.

Pritchard, H. W., and K. R. Manger. 1990. "Quantal Response of Fruit and Seed Germination Rate in Quercus Robur L. And Castanea Sativa MilL. To Constant Temperatures and Photon Dose." Journal of Experimental Botany 41: 1549-1557. doi:10.1093/jxb/41.12.1549.

Ranal, M. A., and D. G. Santana. 2006. "How and Why to Measure the Germination Process?" Revista Brasileira de Botanica 29 (1): 1-11. doi:10.1590/S010084042006000100002.

Ritchie, J. T., and D. S. NeSmith. 1991. “Temperature and Crop Development.” In Modeling Plant and Soil Systems. Agronomy Monograph 31, edited by J. Hanks and J. T. Ritchie, 5-29. Madison (USA): American Society of Agronomy. doi:10.2134/agronmonogr31.c2.

Trudgill, D. L., A. Honek, D. Li, and N. M. Van Straale. 2005. "Thermal Time - Concepts and Utility.” Annals of Applied Biology 146: 1-14. doi:10.1111/j.1744-7348.2005.04088.x. 